\title{
Full-scale testing of adhesively bonded timber-concrete composite beams
}

\author{
Jens Frohnmüller (D) Jens Fischer $\cdot$ Werner Seim
}

Received: 7 January 2021 / Accepted: 29 July 2021 / Published online: 7 September 2021

(C) The Author(s) 2021

\begin{abstract}
This paper presents new findings on adhesively bonded timber-concrete composites with prefabricated concrete parts. Hereby, timber and concrete are bonded solely with adhesive and no metallic connectors have been used. Because the achievement of a continuous bond proved to be a critical point in past studies, special attention is given to that issue. The application procedure of the adhesives is investigated in small-scale bond samples and the manufacturing process in full-scale composite beams with a span of $8 \mathrm{~m}$ and a comparatively new polymer mortar is used as adhesive as well as a common epoxy resin. Both adhesives proved to be suitable, although polymer mortars showed strong advantages in terms of applicability and bridging of gaps in comparison to the less viscous epoxy adhesive. The full-scale beams are tested under quasi-static and cyclic loading. The failure occurred more as a bending failure of the timber or compression failure of the concrete. A full bond could be achieved at all fullscale beams. Moreover, an analytical and a finite element model for the calculation of composite beams are presented and validated. It could be seen, that both deformation behavior and failure load are in good accordance with the test results.
\end{abstract}

J. Frohnmüller $(\bowtie) \cdot$ J. Fischer · W. Seim

Timber Structures and Building Rehabilitation, University of Kassel, Kurt-Wolters-Straße 3, 34125 Kassel, Germany e-mail: frohnmueller@uni-kassel.de
Keywords Adhesively bonded timber-concrete composites · ATCC · Bridge construction · Prefabrication · Gluing technology · Adhesive bond · Hybrid timber structures

\section{Introduction}

The general construction method of timber-concrete composites (TCC) has already been successfully introduced to the building industry and are mainly realized for slabs in residential and commercial buildings [1, 2]. A possible application for TCC constructions could also be found in bridges under dynamic loading, such as when trucks or heavy machinery cross over [3] (see Fig. 1).

\subsection{Motivation}

The motivation of this study is to improve common construction methods for TCC by using adhesives and prefabricated concrete parts (prefabs) instead of screws, bolts or other types of metallic shear connectors or notches, which are commonly used to combine timber and concrete. An overview of the common connection methods can be found in the COSTTechnical Specification [4]. These methods have in common that they require the use of cast-in-place concrete which often leads to longer construction 
Fig. 1 Adhesively bonded timber-concrete composites (ATCC) constructions: a Illustration for possible use in small- and medium span bridges b Full-scale test specimen with a span of $8 \mathrm{~m}$

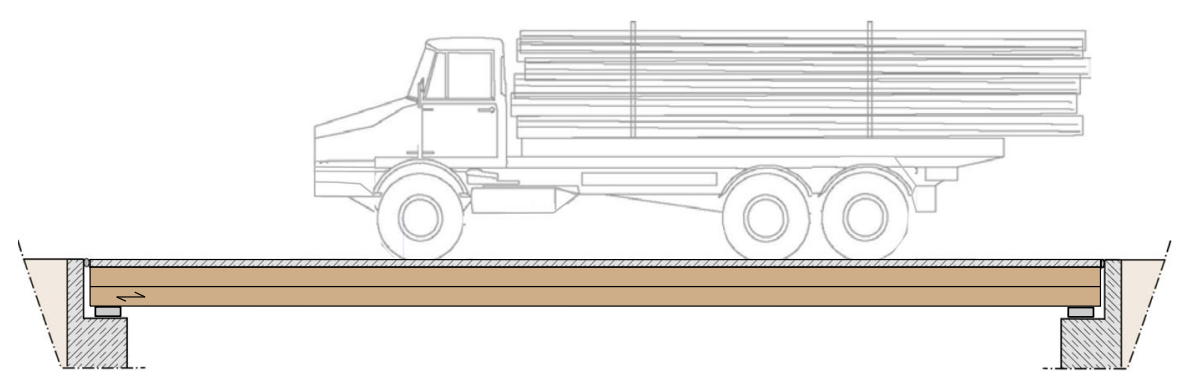

(a)

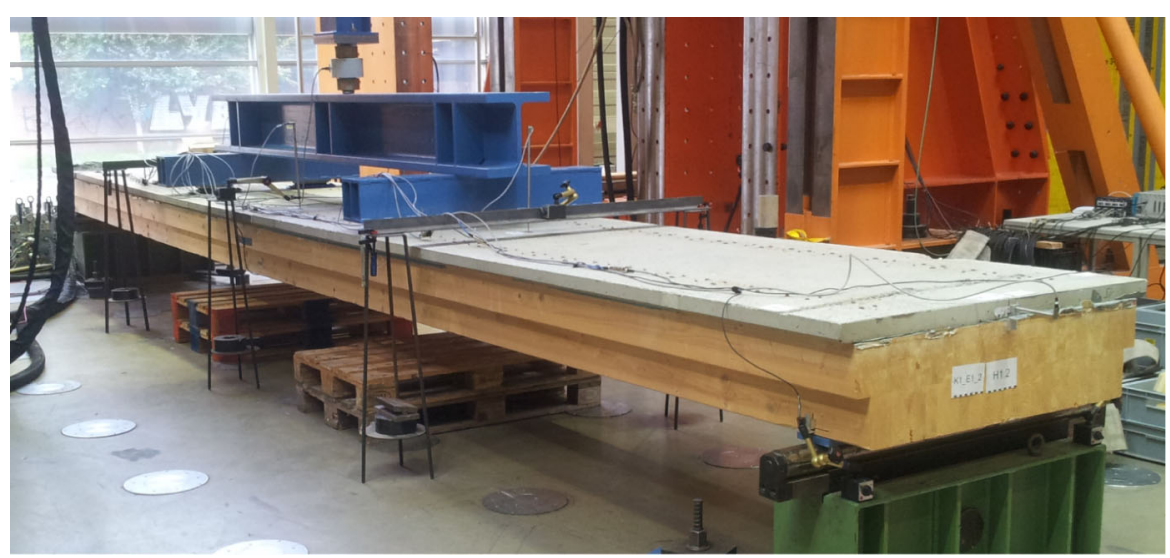

(b) periods compared to typical timber structures. This applies to slabs of multi-story buildings and bridge decks. There is currently only one TCC connection method on the market which can be used with precast concrete elements [4] but it requires a large number of metallic connectors

An interesting alternative to common TCC connectors could be the use of adhesives which leads to adhesively bonded TCC (ATCC). Adhesive bonding provides a rigid connection between timber and concrete and an increase of strength and stiffness, as was reported by Tannert et al. [5], who conducted tests with TCC specimens with screws and ATCC specimens. Basically, two methods are possible to achieve a full bond: the wet-in-wet process (performed, for example, by Brunner et al. [6] or Tannert et al. [5]) and the prefab-bonding process where a prefabricated concrete slab is glued to the timber part. This study will focus on the second option.

Using prefabs instead of pouring the concrete onsite or using mechanical connectors exhibits several advantages, such as an elimination of the concrete's drying process and supports during the hardening time. This reduces the effort of manpower and the construction time significantly. Another positive effect is that the moisture impact on the timber surface is considerably reduced by using prefabs and less shrinkage takes place, respectively. Moreover, concrete prefabs and the timber can be fabricated separately by different companies and transferred directly to the construction site. The logistic effort can, therefore, also be optimized because the joining process can be realized at different places, such as the timber-production works, the concrete factory or the construction site.

In addition to the great advantages, some disadvantages of the ATCC construction method might be found in the possible deterioration of the adhesive bond due to fire or variable environmental conditions. While the fire resistance of the adhesive bond plays only a minor role in bridge constructions, it becomes more important regarding floors and slabs in multistory buildings. The load-bearing capacity of the adhesive under fire conditions cannot be guaranteed. 
However, the timber part of the ATCC construction method is very often strong enough to ensure the resistance required without needing the composite action. The behavior of ATCC beams in variable environmental conditions has already been investigated in first steps by Eisenhut [7]. Although the focus was laid on the long-term deflections rather than the stresses due to the variable climate, the results indicate that a sufficient strength of the adhesive bond remains.

\subsection{State of the art - design and testing of ATCC full-scale beams}

The prefab-bonding method was first investigated by Pincus [8], who performed ATCC bending tests with a span of approximately $4 \mathrm{~m}$ and a high-viscous twocomponent epoxy resin (2EP) as adhesive. The failure modes occurred either as a bending failure of the timber, compression failure of the concrete or as a bond failure in near-surface concrete layers. Because the bond failure did not initiate a global failure of the composite beam, Pincus introduced the term sliding shear failure.

Further investigations into prefab-bonding were carried out by Schäfers and Seim [9], who investigated the adhesive bond of 2EP with ultra-high performance concrete in bending tests with a span of $3.8 \mathrm{~m}$, whereby the failure always occurred in the timber.

Bending tests with a span of $10 \mathrm{~m}$ were carried out by Ben Mekki and Toutlemonde [10] with a carbon fiber reinforced, high-performance concrete and a timber beam, which was reinforced with carbon fiber reinforced polymer lamellas. The authors report the gluing process to be quite challenging because the unevenness of the concrete surface led to gaps in the joint, resulting in unbonded areas. The lack of continuous contact between timber and concrete was then eliminated by applying layers of filling compound with epoxy ingredients on top of the timber to compensate for the uneven concrete surface. This layer was applied $24 \mathrm{~h}$ before actually gluing the concrete onto the modified timber part. An extensive analysis was not possible due to problems with the manufacturing.

Negrão et al. [11] manufactured ATCC beams with a span of $4 \mathrm{~m}$. In order to prevent unbonded areas, such as those reported by Ben Mekki and Toutlemonde [10], the authors spread the adhesive abundantly and applied either great pressure with heavy weights put on top of the concrete plate during the hardening of the adhesive or with Dywidag cables anchored to the concrete. Full contact could be achieved in this way. Failure occurred as a bending failure in the timber or a shear failure in near-surface concrete layers, although the shear stress at failure was lower than expected from the previous bond tests. Linear-elastic material properties were assumed in the numerical model but the interaction of tension and bending stresses as recommended in Eurocode 5 [12] has not been considered. The material properties were roughly estimated as $33 \%$ greater than characteristic values.

Eisenhut et al. [7] investigated the long-term behavior of ATCC beams in bending tests with a span of $4.0 \mathrm{~m}$ in variable environmental conditions. The specimens were fabricated with the help of spacers to define the joint thickness and then stored over a stream for about two years. A delamination of the adhesive joint took place at one beam. Eisenhut documented that too much adhesive was pressed out of the joint during the manufacturing process while fixing the slab to the timber with screw clamps.

Kästner and Rautenstrauch [13] and Kästner [14] used polymer mortars (PM) for bonding timber and concrete prefabs with and exposed aggregate concrete surface and longitudinal grooves in the timber part. Two specimens with a joint thickness of $13 \mathrm{~mm}$ and no other connectors were manufactured and tested in bending tests with a span of $4.80 \mathrm{~m}$. The failure occurred as a bending failure in the timber or as a shear failure in both timber and concrete.

\subsection{Objective}

Despite the advantages of ATCCs with prefabs and the progress which has been made in the past few years in this field there are still open questions which hinder the application of the ATCC construction method in bridge constructions. This research aims to answer the question how a full bond between timber and concrete can be achieved and how the behavior of ATCC beams can be predicted in both failure load and deformation behavior. Related to this objective, the following topics can be listed:

Manufacturing method: The unevenness of the concrete plate has a great influence on achieving a full and continuous bond with the timber part. This issue was detected at the end of the project by Ben Mekki and 
Toutlemonde [10] hindering a complete analysis of the composite beams. It became clear, that the gluing and manufacturing process at the beginning of every testing proved to be essential for the success of the construction method. Therefore, this research aims to find a robust manufacturing method.

New materials: The use of PM as an adhesive for bonding timber and concrete is new. The high viscosity allows for the design of clearly defined geometries of the bonding area.

\section{Bonding of planar structures instead of beams:}

To the best of the authors' knowledge, the linear bonding of timber to concrete surfaces has never been reported before. Hence, this study aims to extend the state of the art to large, plane surfaces, where the evenness is likely to be considerably more critical than it is for beams.

Full-scale testing: So far, most tests were performed with a span of about $4 \mathrm{~m}$. This study aims to extend the dimensions for the full-scale testing of ATCC.

Modelling: Two models will be presented in this study. In the models, an assumption of linear-elastic material behavior seems to be reasonable due to the comparatively brittle behavior of ATCC beams. If basic mechanical models are suitable to predict the load bearing, the capacity and stiffness will be studied. Furthermore, shear deformations will be considered in the calculation and discussed.

\section{Materials and methods}

The experimental campaign is divided in two series to achieve the goal of producing full-scale beams with a fault-free adhesive bond: 42 small-scale bond tests and 5 full-scale composite beams. Two adhesives were investigated for both series: A common low-viscous 2EP [15] and a high-viscous PM [16]. The advantages of low-viscous adhesives are generally good wetting and penetration behavior into the adherents. The advantages of high-viscous adhesives are their geometrical stability over time and gap-filling behavior.

\subsection{Experimental campaign}

\subsubsection{Small-scale bond samples}

A first series of small-scale bond samples was carried out to determine a method for the adhesive application and distribution, a suitable geometrical pattern of the adhesive and an appropriate thickness of the adhesive joint. These tests were carried out as bond tests. Their impact on the failure load can be determined by varying these parameters. All 42 tests were carried out with different configurations. The test setup and the different configurations are depicted in Fig. 2, and the results are documented in Sect. 3.1.4.

\subsubsection{Full-scale composite beams}

The aim of the second test series with ATCC full-scale composite beams is to map a bridge with a span of $8 \mathrm{~m}$ in a 1:1 test in the laboratory. These were carried out as bending tests and can also be interpreted as a scaled testing of a bridge with a span of $16 \mathrm{~m}$ (see Kühlborn and Seim [17]). The manufacturing and gluing process was customized regarding the results of the bond tests. Accordingly, a reliable bonding was reached considering the gap's size between timber and concrete. The height profile of two slabs was measured in advance via laser scanning to determine the evenness of the concrete slab. The adhesive application of the PM was then adjusted regarding the specific height profile.

The basic load-bearing behavior of the composite deck was tested under quasi-static loading. Moreover, cyclic loading intended to support the development of a pilot project where the bridge is part of a forest road. The number of cycles was calculated for a total number of bridge crossings which would occur approximately in the lifetime of a typical forestry bridge over 50 years under heavy traffic such as lumber trucks or harvesters. The number expected depends on parameters such as the size of the catchment area, local cutting frequency (in this case $6 \mathrm{~m}^{3} / \mathrm{ha} / \mathrm{a}$ [18]) and a lumber truck's capacity. The size of an average catchment area was determined regarding several areas where comparable bridges could be found. Taking into account these parameters, a rough estimate of a total of 2,500 truck crossings over the lifespan was calculated. 


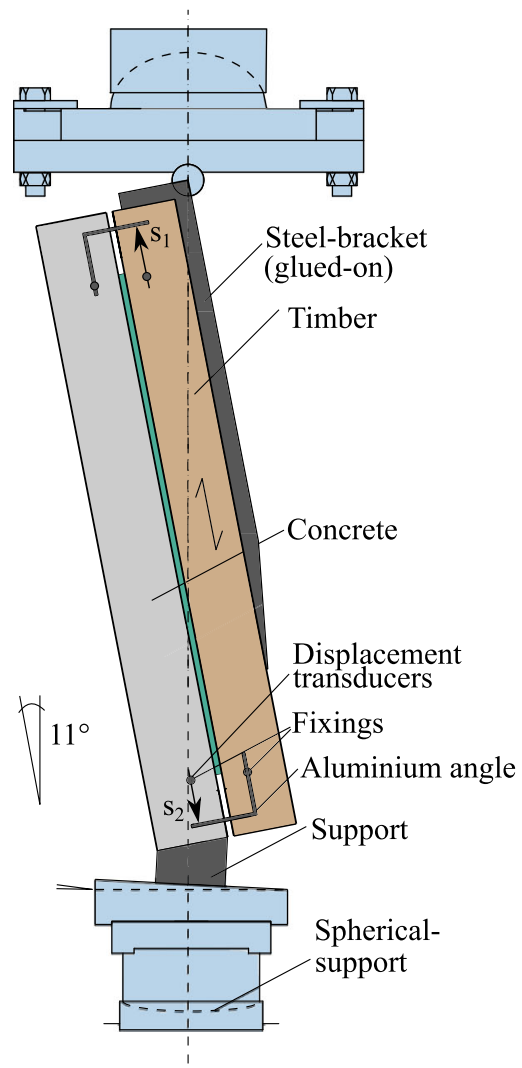

A

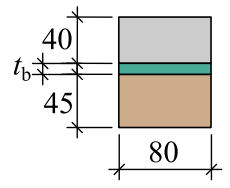

B

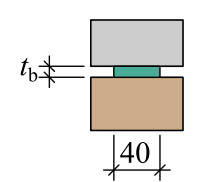

C

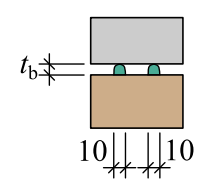

D

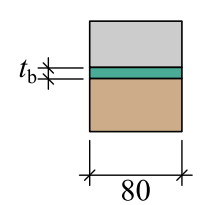

$\mathbf{E}$

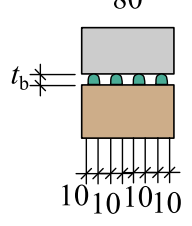

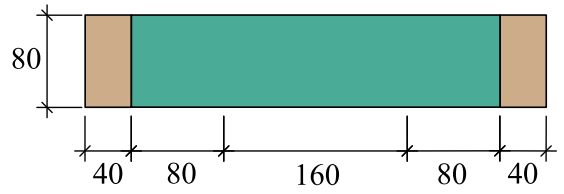
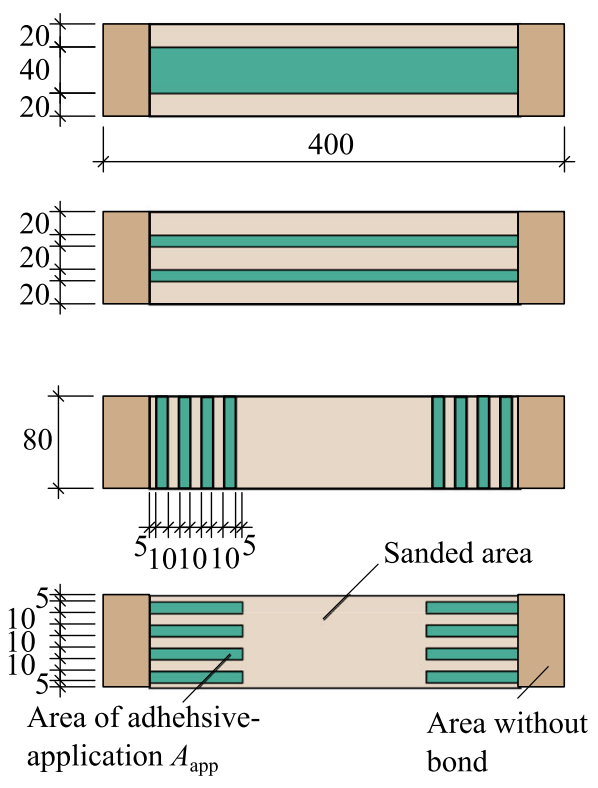

Fig. 2 Bond tests-Test setup, geometries and naming of the specimens

\subsection{Materials}

\subsubsection{Timber}

The material parameters of the timber $\mathrm{C} 24$, which was used for the bond samples, were determined experimentally according to EN 408 [19].

The block glued glulam beams to be used for the full-scale composite beams were ordered in the quality GL26h. The strength class of the beam was checked according to EN 408 [19] by the determination of the density, whereby the samples were taken from the beams after conducting the bending tests.

The Young's modulus $E$ was calculated from the bending behavior of the glulam beam as described in EN 408, section 10. The shear modulus $G$ is taken according to Eurocode 5 [12] as $680 \mathrm{~N} / \mathrm{mm}^{2}$.

Regarding the characteristic value of the bending strength $f_{m, k}=26 \mathrm{~N} / \mathrm{mm}^{2}$, using the statistical factor for a large sample $k_{n}=1.64$ and the recommended coefficient of variation for glulam beams of $\mathrm{COV}=$
0.15 from the JCSS probabilistic model code [21], together with a lognormal distribution, the mean value for the bending strength can be calculated according to EN 14358 [20] as $f_{\text {m,mean }}=33.3 \mathrm{~N} / \mathrm{mm}^{2}$ :

$f_{m, \text { mean }}=e^{\left(\ln \left(f_{m, k}\right)+k_{n} \cdot s\right)}$

with the standard deviation $s$ in logarithmic form:

$s=\sqrt{\ln \left(1+C O V^{2}\right)}$

The $C O V$ which is recommended in JCSS is in good accordance with the $C O V$ of 0.15 which was calculated for the density tests. Tension and shear strength were determined regarding JCSS to $f_{t, 0}=0.6 \cdot f_{m}$ and $f_{v}=0.2 \cdot f_{m}{ }^{0.8}$. All values are summarized in Table 1 .

\subsubsection{Concrete}

The concrete parts for the bond samples and the fullscale composite beams consist of the same mixture with the strength class $C 45 / 55$. The grading curve was 
Table 1 Timber-mean values

\begin{tabular}{lll}
\hline & $\begin{array}{l}\text { C24 } \\
\text { (Bond samples) }\end{array}$ & $\begin{array}{l}\text { GL26h } \\
\text { (Composite beams) }\end{array}$ \\
\hline$E\left[\mathrm{~N} / \mathrm{mm}^{2}\right]$ & $11,272(n=3$, COV $=5.9 \%)$ & $12,220^{\mathrm{a}}$ \\
$G\left[\mathrm{~N} / \mathrm{mm}^{2}\right]$ & - & 680 \\
$f_{t}\left[\mathrm{~N} / \mathrm{mm}^{2}\right]$ & - & $20.0^{\mathrm{c}}$ \\
$f_{m}\left[\mathrm{~N} / \mathrm{mm}^{2}\right]$ & - & $33.3^{\mathrm{b}}$ \\
$f_{v}\left[\mathrm{~N} / \mathrm{mm}^{2}\right]$ & $4.4(n=4, C O V=13.4 \%)$ & $3.3^{\mathrm{c}}$ \\
$\rho_{12}\left[\mathrm{~kg} / \mathrm{m}^{3}\right]$ & $391(n=5, C O V=3.5 \%)$ & $441(n=13, C O V=15.0 \%)$ \\
\hline
\end{tabular}

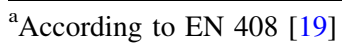

${ }^{\mathrm{b}}$ According to EN 14358 [20]

${ }^{\mathrm{c}}$ Calculated according to JCSS [21]

chosen as A/B 16 with an upper limit of the $w / c$ ratio of $0.45,440 \mathrm{~kg} / \mathrm{m}^{3}$ CEM II A/LL-52.5N cement and 3.84 $\mathrm{kg} / \mathrm{m}^{3}$ plasticizer. The bottom surfaces of the prefabs, which were in contact with the formwork, were sandblasted until an exposed aggregate surface was achieved. This process is recommended in the classical concrete-to-concrete construction method to generate a rough surface and increase the friction. In this case, the roughness of the surface has not been the reason for the sandblasting since the adhesive bond transfers the forces by adhesion rather than friction. Nevertheless, the sandblasting is also recommended for adhesively bonded surfaces to remove oils, release agents and the potentially weaker surface due to a concentration of calcium hydroxide in the outer concrete layer (see Rehm and Franke [22]). Moreover, Kästner [14] recommends not only sandblasting but also priming the surface. This recommendation was not followed and all specimens were glued without using a primer.

The mean value of the surface's tensile strength $f_{c t m, \text { surf }}$ was determined experimentally to $2.0 \mathrm{~N} / \mathrm{mm}^{2}$ $(n=12, C O V=20 \%)$.

The mean value of the concrete's compression strength is calculated with the assumption of the characteristic compression strength value $f_{c, k}=45 \mathrm{~N} /$ $\mathrm{mm}^{2}$ for strength class $\mathrm{C} 45 / 55$ and the relationship given by Eurocode 2 [23] as $f_{c \text {, mean }}=53.0 \mathrm{~N} / \mathrm{mm}^{2}$.

No further attention to concrete compression strength has been paid because compression failure of the concrete could be excluded during the design procedure.

$f_{c, \text { mean }}=f_{c, k}+8 \mathrm{~N} / \mathrm{mm}^{2}$.

The mean value of the Young's modulus is taken from Eurocode 2 [23] as $36,000 \mathrm{~N} / \mathrm{mm}^{2}$. Another approach can be found in the fib Model Code [24], where $E_{c \text {,mean }}$ is given as $37,500 \mathrm{~N} / \mathrm{mm}^{2}$ for the strength class $\mathrm{C} 45$ / 55. A further recommendation is to consider the factor $\alpha_{i}$ for linear-elastic models where initial, plastic deformations in the concrete part are not taken into account otherwise, for example, by a nonlinear material law. Considering the factor $\alpha_{i}=0.9205$, $E_{c \text {, mean }}$ becomes $37,500 \times 0.9205=34,500 \mathrm{~N} / \mathrm{mm}^{2}$.

$\alpha_{i}=0.8+0.2 \cdot \frac{f_{c, \text { mean }}}{88} \leq 1.0$

The recommendation of [24] is being followed.

The shear modulus $G_{c, \text { mean }}$ is calculated according to Eurocode 2 with $v=0.2$ as $G_{c \text {, mean }}=15,100 \mathrm{~N} / \mathrm{mm}^{2}$ and according to fib Model Code as $G_{c \text {, mean }}=14,375$ $\mathrm{N} / \mathrm{mm}^{2}$, see Eq. 5. All material values of the concrete are summarized in Table 2.

$G_{c, \text { mean }}=\frac{E_{c \text { mean }}}{2 \cdot(1+v)}$

\subsubsection{Adhesive}

The material characteristics of the 2EP are declared by the producer in the technical approval [15]. The mean values of the PM were taken as stated by the producer [16] and according to tests carried out by Kästner [14] and Braun [25]. The values are summarized in Table 3.

\subsection{Analytical modeling}

The elastic beam theory was adapted for the design and the analysis of the full-scale specimen's stress state under loading conditions assuming fully bonded 
Table 2 Mechanical values of the concrete-mean values

\begin{tabular}{llll}
\hline & Eurocode 2 & fib Model Code & Experiment \\
\hline$E_{c}\left[\mathrm{~N} / \mathrm{mm}^{2}\right]$ & 36,000 & 34,500 & - \\
$G_{c}\left[\mathrm{~N} / \mathrm{mm}^{2}\right]$ & 15,100 & 14,375 & - \\
$f_{c t m, \text { surf }}\left[\mathrm{N} / \mathrm{mm}^{2}\right]$ & - & - & $2.0(n=12$, COV $=20.0 \%)$ \\
$f_{c}\left[\mathrm{~N} / \mathrm{mm}^{2}\right]$ & 53.0 & - & - \\
\hline
\end{tabular}

Table 3 Mechanical values of the adhesives-mean values

\begin{tabular}{lllll}
\hline & $2 \mathrm{EP}^{a}$ & $\mathrm{PM}^{b}$ & $\mathrm{PM}^{c}$ & $\mathrm{PM}^{d}$ \\
\hline$E\left[\mathrm{~N} / \mathrm{mm}^{2}\right]$ & 4,500 & $>25,000$ & $32,500(n=6, C O V=1.8 \%)$ & - \\
$f_{t}\left[\mathrm{~N} / \mathrm{mm}^{2}\right]$ & 30.0 & $>35.0$ & $16.8(n=3, C O V=13.5 \%)$ & - \\
$f_{c}\left[\mathrm{~N} / \mathrm{mm}^{2}\right]$ & $\geq 30.0$ & $>130.0$ & $140.5(n=6, C O V=4.1 \%)$ & $144.0(n=6, C O V=2.2 \%)$ \\
$f_{v}\left[\mathrm{~N} / \mathrm{mm}^{2}\right]$ & $\geq 12.0$ & - & $26.4(n=5, C O V=1.7 \%)$ & - \\
$f_{m}\left[\mathrm{~N} / \mathrm{mm}^{2}\right]$ & - & - & - & $33.9(n=3, C O V=9.0 \%)$ \\
\hline
\end{tabular}

${ }^{\mathrm{a}}$ As stated by the producer [15] for Sikadur 330

${ }^{\mathrm{b}}$ As stated by the producer [16] for Epument 130/3 A1

${ }^{\mathrm{c}}$ Experimentally determined by Kästner [14] for Epument 140/5A1

${ }^{\mathrm{d}}$ Experimentally determined by Braun [25] for Epument 130/3 A1

beam sections. This assumption is backed up by the existence of a full, rigid bond between timber and concrete, which is characterized by the brittle failure behavior with more or less linear-elastic behavior until reaching the ultimate load. Furthermore, a 2D finite element (FE) model was created to calculate the deformation and stresses assuming linear-elastic material behavior. Details of the modeling are explained in Sects. 4.1 and 4.2.

\section{Experimental investigations}

\subsection{Bond tests}

\subsubsection{Conceptual design}

A total of 42 test specimens were designed considering five geometric patterns of the area $A_{a p p}$ where the adhesive has been applied (see Fig. 2; Table 4). The PM was used as an adhesive for series A and B the PM was used as adhesive and the $2 \mathrm{EP}$ for $\mathrm{C}, \mathrm{D}$ and $\mathrm{E}$. The thickness of the adhesive bond $t_{b}$ was defined as 5.0, 7.5 and $10.0 \mathrm{~mm}$ for series A and B and 2.0, 4.0 and 6.0 $\mathrm{mm}$ for series $\mathrm{C}, \mathrm{D}$ and $\mathrm{E}$. Three specimens were manufactured for each combination.

$$
F_{u, e s t}=\frac{f_{v, \text { mean }} \cdot A_{\text {app }}}{\cos \left(11^{\circ}\right)}
$$

The failure load $F_{u, e s t}$ is estimated based on the bonded adhesive surface $A_{\text {app }}$, the mean shear strength of the timber $f_{v \text {,mean }}$ and the angle of the specimen in the test setup. According to this estimation, it becomes possible to evaluate the failure loads later in this study.

\subsubsection{Manufacturing and gluing process}

The timber was prepared by planing the wooden surfaces before gluing. The sandblasted concrete surface was cleaned with oil-free compressed air to remove loose residuals. The adhesive was applied to the timber part according to the defined pattern of series A-E, whereby the PM was applied by a spreader-tool and the 2EP with a toothed spatula. The spatula left an adhesive rope with a height of 7.5 $\mathrm{mm}$ and a width of $10 \mathrm{~mm}$. The distance between each rope was also $10 \mathrm{~mm}$. An unbonded area at the beginning and the end of the specimens was ensured by sellotaping. The concrete part was then put on the timber part by manual pressure. The thickness of the joint was defined by spacers. The L-shaped steel bracket and support block were glued on the next day; 
Table 4 Overview-full testing program

\begin{tabular}{|c|c|c|c|c|c|c|}
\hline \multicolumn{3}{|c|}{ Bond tests } & \multicolumn{4}{|c|}{ Full-scale beams } \\
\hline Series & $t_{b}$ & $n$ & Labelling & Bonding area & Loading & $\mathrm{n}$ \\
\hline \multirow[t]{3}{*}{ A } & $5.0 \mathrm{~mm}$ & 3 & FB-2EP-1 & full & Stat. & 1 \\
\hline & $7.5 \mathrm{~mm}$ & 3 & FB-2EP-2 & lat. & Cycl. (+ stat.) & 1 \\
\hline & $10.0 \mathrm{~mm}$ & 3 & FB-2EP-3 & lat. & Stat. & 1 \\
\hline \multirow[t]{2}{*}{$\mathrm{B}$} & $5.0 \mathrm{~mm}$ & 3 & FB-PM-1 & long. & Stat. & 1 \\
\hline & $7.5 \mathrm{~mm}$ & 3 & FB-PM-2 & long. & Cycl. (+ stat.) & 1 \\
\hline \multirow[t]{3}{*}{$\mathrm{C}$} & $2.0 \mathrm{~mm}$ & 3 & & & & \\
\hline & $4.0 \mathrm{~mm}$ & 3 & & & & \\
\hline & $6.0 \mathrm{~mm}$ & 3 & & & & \\
\hline \multirow[t]{3}{*}{$\mathrm{D}$} & $2.0 \mathrm{~mm}$ & 3 & & & & \\
\hline & $4.0 \mathrm{~mm}$ & 3 & & & & \\
\hline & $6.0 \mathrm{~mm}$ & 3 & & & & \\
\hline \multirow[t]{4}{*}{$\mathrm{E}$} & $2.0 \mathrm{~mm}$ & 3 & & & & \\
\hline & $4.0 \mathrm{~mm}$ & 3 & & & & \\
\hline & $6.0 \mathrm{~mm}$ & 3 & & & & \\
\hline & $\Sigma$ & 42 & & & $\Sigma$ & 5 \\
\hline
\end{tabular}

the width of both parts was $50 \mathrm{~mm}$. The test was carried out after a total curing time of seven days.

\subsubsection{Test set-up and loading}

The test set-up was designed according to $E N 408$ [19] and modified to fit the needs of the ATCC construction. The load was applied with a constant velocity of $0.01 \mathrm{~mm} / \mathrm{s}$ and the relative displacement was recorded by four displacement sensors, which were installed on the front $(S 1, S 2)$ and the back of the specimens $(S 3$, S4).

\subsubsection{Results}

The failure loads of the bond tests in comparison with the estimated failure load $F_{u, e s t}$ are shown in Fig. 3. The bond failure of the specimens occurred in three different ways: as shear failure parallel to the grain in timber, as near-surface shear failure in the concrete or as a combination of both, see Fig. 4. The relative displacement reached values of about $0.1-0.5 \mathrm{~mm}$, whereby the displacement of the sensors near the load application $(S 1, S 3)$ were slightly higher.

Most of the specimens of series C, D and F, where 2EP adhesive was applied in strips exhibited a higher failure load compared to the prediction. Furthermore, it could be seen that a decrease in layer thickness $t_{b}$ leads to a considerable increase of the magnitude of failure. This can be explained by the widening of the strips when the two parts are pressed against each other resulting in an increasing effective bonding area $A_{b}$ compared to the area where the adhesive was applied initially $A_{\text {app }}$.

In the special case of series D-6.0, all failure loads fall below $F_{u \text {,est }}$ which means that the specimens did not even reach the minimum bond strength defined by $F_{u \text {,est }}$. This is a sign, that the bonded surface $A_{b}$ is smaller than the area of initial adhesive application $A_{\text {app }}$. This is underlined by the fracture pattern shown in Fig. 4c, where areas of no contact between adhesive and concrete can be seen.

It can be stated in conclusion that both adhesives are basically suitable for bonding timber and concrete. In order to reach a full bond, the 2EP has to be applied with a toothed spatula, whereas the PM can be applied in larger strips. The total thickness of the joint seems to be secondary as long as there is full contact between timber and concrete. The failure then occurs solely in the substrates timber and concrete, and the bond strength could be equated to the shear strength of the timber for the material configuration of sandblasted concrete with the strength class $\mathrm{C} 45 / 55$ and timber C24. 
Fig. 3 Bond tests-results

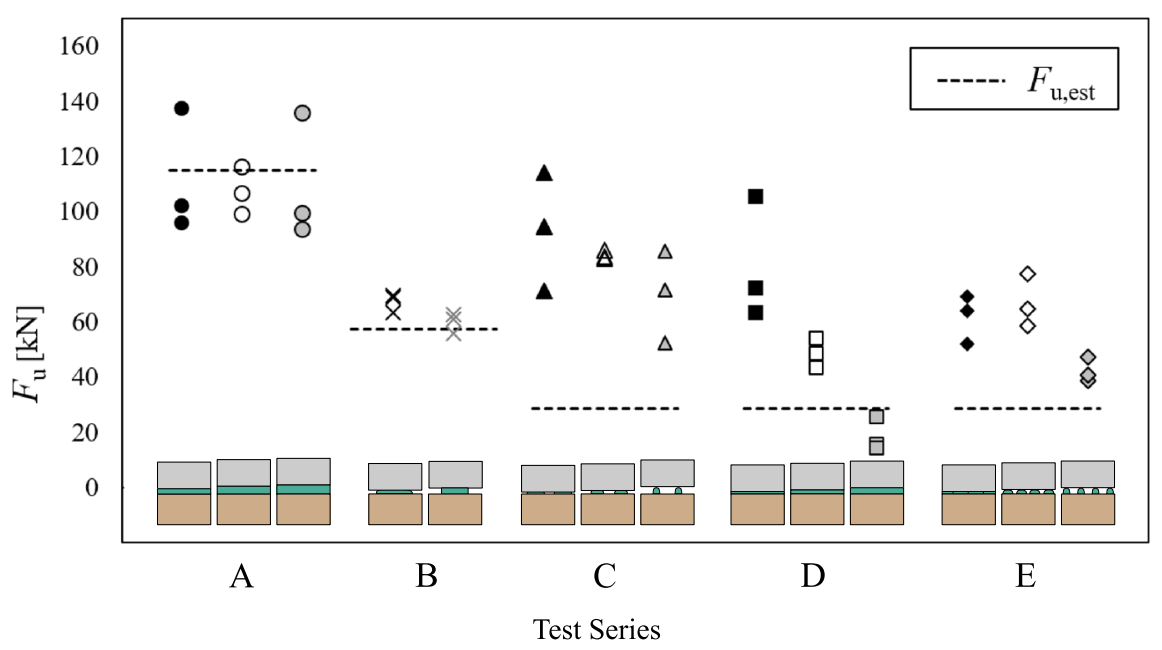

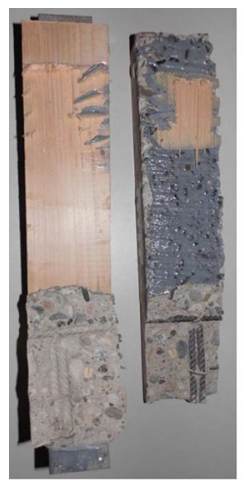

(a)

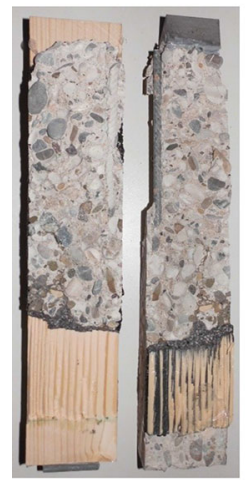

(d)

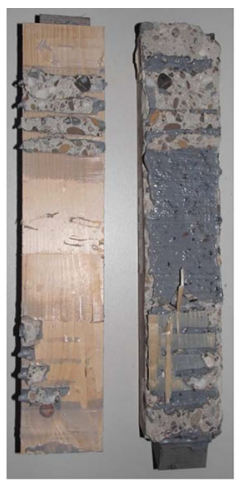

(b)

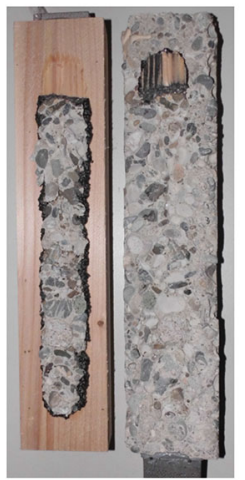

(e)

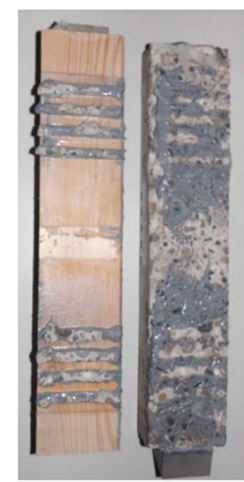

(c)

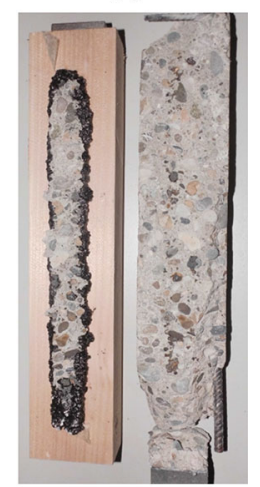

(f)
Fig. 4 Bond tests-typical failure modes of series a D-2.0, b D4.0, c D-6.0, d A-7.5, e B-5.0 and f B-7.5
3.2 Full-scale bending tests

\subsubsection{Manufacturing process}

Five full-scale beams (FB) were manufactured using the adhesives 2EP and PM and three different patterns for the bonding area. The labeling of the specimens is displayed in Fig. 4. The beams are specified regarding the geometry of the bonded area (whole surface bonded $=f u l l$, lateral adhesive stripes $=$ lat., longitudinal adhesive stripes =long.) and their loading (cyclic $=$ cycl. , quasi-static $=$ stat.$)$.

The concrete plates were produced with the dimensions of $4.08 \mathrm{~m}$ length, $1.20 \mathrm{~m}$ width and a thickness of $5 \mathrm{~cm}$. Two lattice girders were part of the concrete plates to stiffen the plates during transport (see Fig. 5). Additionally, anchor sleeves had been installed at each narrow side to be used as anchor points for the crane. Each specimen is composed of a timber beam and two concrete plates. The middle part of the beam between the concrete plates was concreted after the gluing process had been finished and no adhesive was applied in this area. The moisture content of the timber at the day of gluing was between 8.3 and $9.8 \%$.

Since the evenness of the surface of the components plays a crucial role in the success of the manufacturing process, the height profile of the timber and the concrete were measured for specimens FB-PM-1 and FB-PM-2 via laser-scanning technology (see Fig. 6). It was discovered that the deviation was less than 1 $\mathrm{mm}$ for the timber part, whereas the concrete surface 

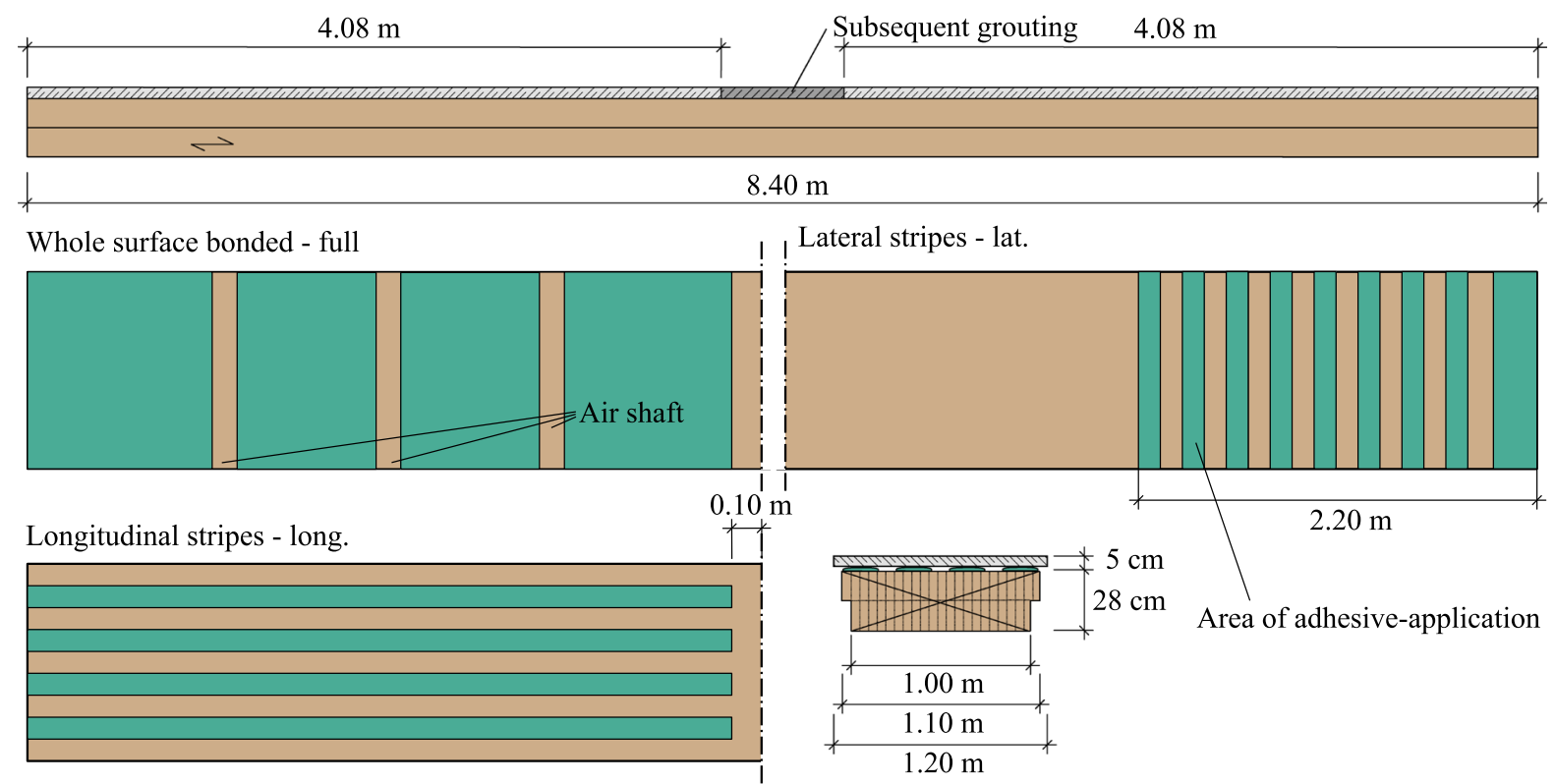

Fig. 5 Full-scale beams (FBs): Geometries of the adhesive joint and naming of specimens

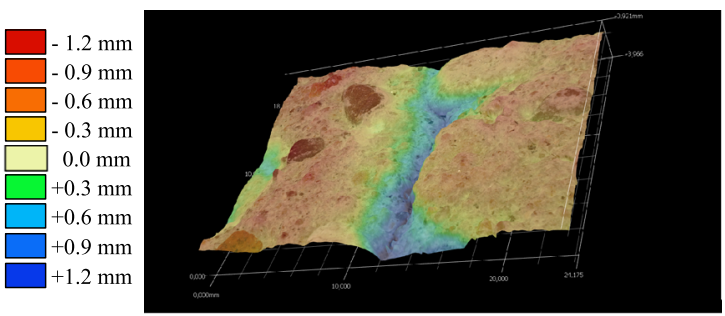

(a)

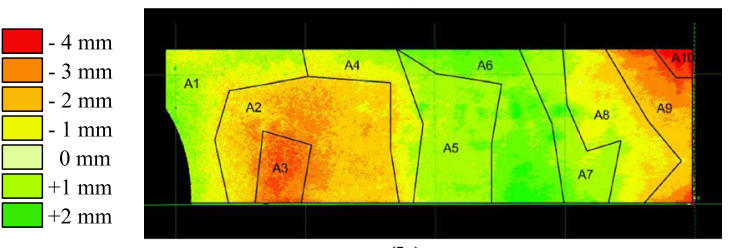

(b)
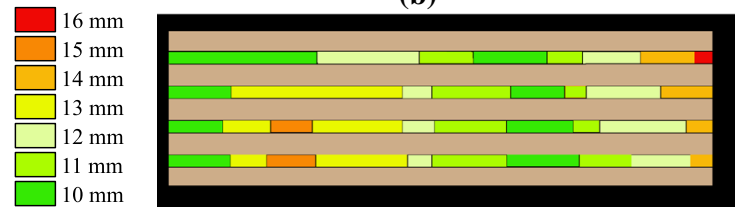

(c)

Fig. 6 Specimen $F B-P M$-1-Height profiles: a Detail of the laser scanning, b Laser-scan of the whole slab; bottom view, c predefined thickness of the glue line

exhibited certain variations. Moreover, isolated grooves and furrows have been detected which should not affect the bonding (see Fig. 6a). The unevenness of the whole concrete surface was determined to be about $\pm 3 \mathrm{~mm}$ in total (see Fig. $6 \mathrm{~b}$ ).

\subsubsection{Gluing process-specimens with PM}

Regarding the adhesive application, wooden battens of different heights were fixed on both sides of each glue line to ensure the thickness and width of the adhesive layer required as depicted in Fig. 7a. The battens were uninstalled after the adhesive had been applied (see Fig. 7b). About $100 \mathrm{~kg} \mathrm{PM}$ was used per specimen.

\subsubsection{Gluing process-specimens with $2 E P$}

The same toothed spatula was used for the application of the adhesive to the full-scale beams as was used for the manufacturing of the bond tests. The 2EP was applied on the timber and the concrete part in strips which had total widths of $15 \mathrm{~cm}$ (see Fig. 7c). In the case of the specimen FB-2EP-1, the adhesive was applied continuously, but without a spatula. As depicted in Fig. 7d, large areas without contact could be seen after the slab was lifted once to check the contact. These gaps were filled with more adhesive and the slab was placed on the timber again. Accordingly, a full bond could be achieved using a large amount of adhesive. 


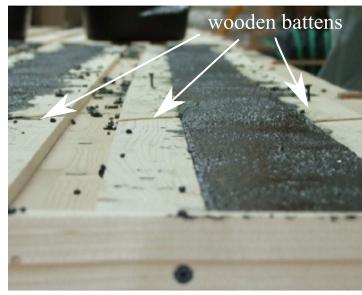

(a)

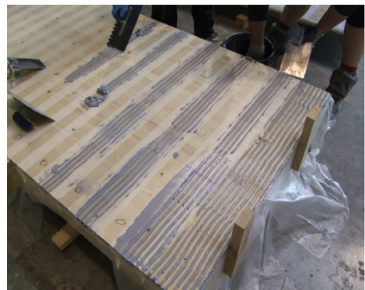

(c)

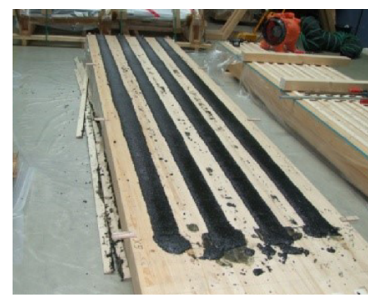

(b)

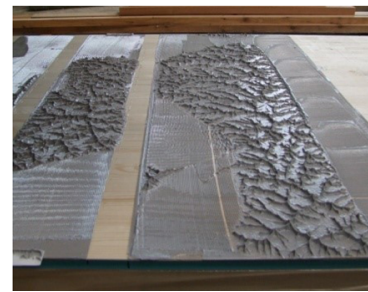

(d)
Fig. 7 Manufacturing of the full-scale specimens with a PM strips with wooden battens, b PM after removal of the battens, c 2EP lateral strips and d 2EP full surface

\subsubsection{Test set-up and loading}

The specimens were tested in a four-point bending configuration, according to EN 408 [19], as depicted in Fig. 8. In order to place the load-inducing steel device directly on the concrete, the lattice girders have been partly cut or completely removed (see Fig. 1b). Therefore the impact on the beams' stiffness can be neglected. Elastomeric pads were placed between the steel and concrete at the loading points and also at the supports at the end of the timber beam for a uniform load-distribution. The force was measured by a load cell with a measurement range up to $1 \mathrm{MN}$. The deflections were measured with 12 displacement transducers: S0 - Displacement of the hydraulic cylinder, S1/S2 - Displacement midspan, S3/S4 Displacement at loading points, S6/S7/S8/S9 - Compression of the supports, S10/S11 - Relative displacement concrete/timber. The midspan deflection $w_{u}$ is calculated as the average of the transducers S1 and S2.

The specimens were loaded in a quasi-static procedure with a constant velocity of $0.1 \mathrm{~mm} / \mathrm{s}$ until $200 \mathrm{kN}$, the load was then reduced to $50 \mathrm{kN}$ and increased again. This procedure was repeated seven times before finally loading up to global failure. The amplitude of the specimens loaded in a cyclic procedure was chosen between 0 and $200 \mathrm{kN}$ with a frequency of $0.1 \mathrm{~Hz}$. The number of cycles was 2,500. After the cyclic procedure, the load was applied with a constant velocity of $0.1 \mathrm{~mm} / \mathrm{s}$ until the ultimate load was reached.

\subsubsection{Results}

The results of the maximum load $F_{u, \exp }$ (S0), the deformation parameter $\Delta w_{1 / 2}$ according to Eq. 7 and
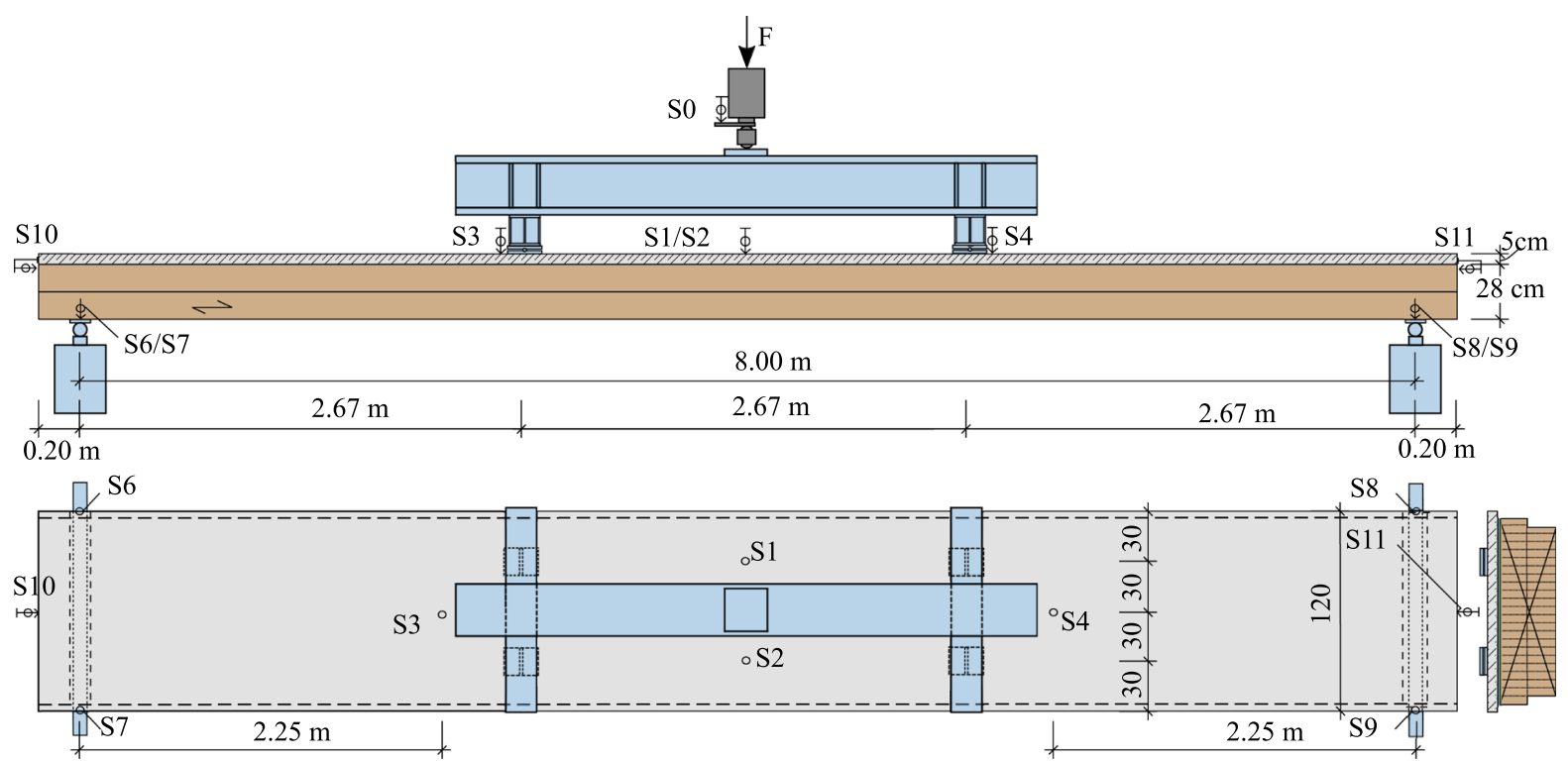

Fig. 8 Test set-up 
Table 5 Results of the bending tests

${ }^{\mathrm{a}}$ For $\Delta F_{1 / 2}=100 \mathrm{kN}$

${ }^{\mathrm{b}}$ Local failure of a timber lamella, no global failure

\begin{tabular}{lllllll}
\hline Specimen & & & $F_{u, \exp }[\mathrm{kN}]$ & Mode & $\Delta w_{1 / 2, \exp }[\mathrm{cm}]^{\mathrm{a}}$ & $w_{\text {u,exp }}[\mathrm{cm}]$ \\
\hline FB-2EP-1 & Stat. & Full & 465 & $T T$ & 1.74 & 9.25 \\
FB-2EP-2 & Cycl. & Lat. & 401 & $C C$ & 1.78 & 8.13 \\
FB-2EP-3 & Stat. & Lat. & 422 & $C C$ & 1.77 & 8.54 \\
FB-PM-1 & Stat. & Long. & 500 & $T T$ & 1.75 & 9.76 \\
FB-PM-2 & Cycl. & Long. & $405^{\mathrm{b} / 440}$ & $\mathrm{TT}^{\mathrm{b}} / C C$ & 1.65 & $7.63^{\mathrm{b}} / 8.92$ \\
Mean Value & & & 446 & & 1.74 & 8.92 \\
\hline
\end{tabular}

the midspan deflection at the point of failure $w_{u, \exp }(\mathrm{S} 1$, S2) are documented in Table 5.

$$
\Delta w_{1 / 2}=w_{2}-w_{1}
$$

The settlement of the supports (S6 - S9) was around a maximum of $1.0 \mathrm{~mm}$. The relative displacement between timber and concrete (S10, S11) served to control the loading procedure but was very small, at a maximum of with $0.01 \mathrm{~mm}$. The sensors S3 and S4 at the beams' end were not used for further analysis.

The failure of the specimens was announced by cracking noises in the timber part and cracking and splitting of the concrete beginning at a loading level of about $350 \mathrm{kN}$. Failure modes are depicted in Fig. 9 and the load-displacement curves can be found in Fig. 13. The failure occurred in all cases in the substrates timber and concrete and never as a bond failure in the adhesive joint. This was checked controlling the relative displacements in a longitudinal direction with the sensors S10 and S11.

The specimens FB-2EP-2 and FB-2EP-3, which were manufactured with lateral adhesive stripes, showed a compression failure in the concrete (CC) (see Fig. 9b). The compression failure in all cases was initiated locally at the anchoring sleeves, which formed unexpected weak areas of the concrete plate. Moreover, both specimens showed signs of buckling in the upwards direction of the concrete plate in the middle of the span where no adhesive was applied.

A tension/bending failure in the timber (TT) could be seen in the three other specimens (see Fig. 9a).

Regarding the load-displacement behavior, all five tests exhibited similar, quasi linear-elastic behavior (see Fig. 13). The deformation characteristics of the composite beams can be determined in the form of the parameter $\Delta w_{1 / 2, \exp }$, which is the deflection in the range of $10 \%\left(w_{1}\right)$ and $40 \%\left(w_{2}\right)$ of the ultimate failure load $F_{u}$. The parameter $\Delta w_{1 / 2, \text { exp }}$ is related to a load of $\Delta F=100 \mathrm{kN}$.
Another point which could be noted is that although the cyclic loading of the two specimens did not affect the deformation behavior, the ultimate failure load $F_{u}$ of both specimens FB-2EP-2 and FB-PM-2 was about $10 \%$ smaller than the average failure load of all specimens $F_{u \text {,mean }}=446 \mathrm{kN}$.

\subsection{Delamination tests}

Eight specimens were cut out of the composite beams after the bending tests had been finished and checked in delamination tests according to EN 14080, Annex C, cycle B [26], whereby four specimens had 2EP as the adhesive, and the other four had PM. After the test procedure, it could be noticed that the specimens with PM remained undamaged (see Figs. 9c and 9e). On the contrary, the specimens with 2EP showed cracks parallel to the joint and a failure in the layers of the concrete near the surface (see Figs. 9d and 9f).

Although the specimens with PM exhibited a good resistance under this comparatively extreme exposure to temperature- and moisture-induced stresses, it seems to be highly questionable whether the delamination test, as designed for the quality control of the adhesive joints of glulam, is suitable to assure the quality of ATCC bonding. This can be explained using the example of the specimens with 2EP which showed an early failure in the substrates. The actual adhesive bond could not, therefore, be evaluated with certainty.

How far the thickness of the adhesive layer affects the durability could not be determined with certainty, although the results indicate that there is a relationship between the joint thickness and moisture-induced stresses. 
(a)

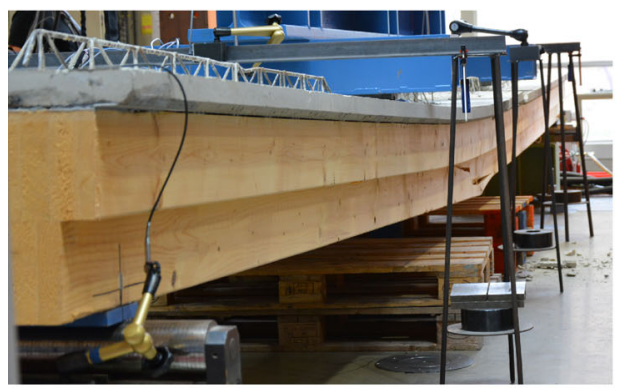

(c)

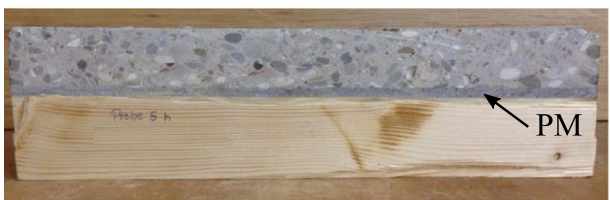

(e)

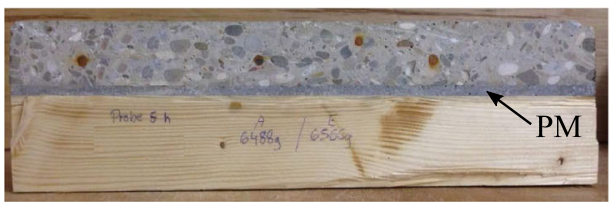

(b)

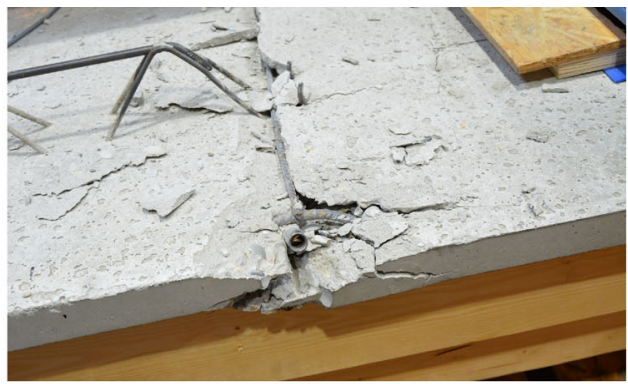

(d)

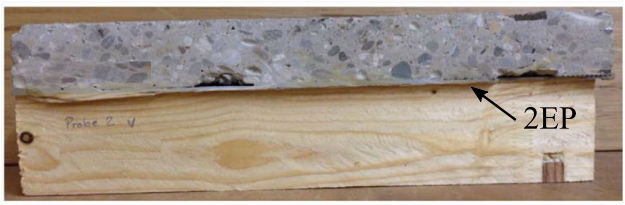

(f)

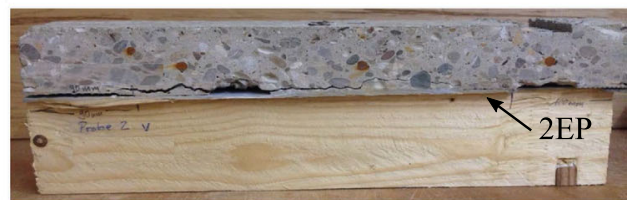

Fig. 9 Results: a Failure mode TT, b failure mode CC, $\mathbf{c}$ and $\mathbf{d}$ specimens before the delamination test, $\mathbf{e}$ and $\mathbf{f}$ specimens after the delamination test

\section{Analytical and numerical modeling}

\subsection{Analytical model}

A first approach for the calculation of bending deformations and stresses in the cross-section of the ATCC beams is a comparatively simple analytical beam model. The composite section can be considered with basic, mechanical principles based on linearelasticity because timber and concrete are rigidly coupled due to the adhesive bond.

The neutral axis $z_{0, c}$ of the ATCC composite beam can be found, according to Steiner's theorem, at 12.6 $\mathrm{cm}$ from the upper edge of the concrete part and the calculated bending stiffness $(E I)_{\text {cal }}$ can be determined according to Eq. 8.

$$
(E I)_{\mathrm{cal}}=\sum_{i=1}^{i} E_{i} \cdot I_{i}+E_{i} \cdot A_{i} \cdot a_{i}^{2}
$$

Figure 10 depicts all geometrical dimensions, whereby $a_{i}$ is the distance between the neutral axis of the whole section and those of the individual parts together with their specific E-Modulus $E_{i}$ and their cross section area $A_{i}$.

With the knowledge of $(E I)_{\text {cal }}$, the bending stresses $\sigma_{i}$ can be calculated at each point of the cross- section. The maximum stresses on the top and the bottom part of the cross-section can be determined if the distances $z_{0, c}$ and $z_{0, t}$ are inserted for $z$ into Eq. 9.

$\sigma_{i}=M \cdot z \cdot \frac{E_{i}}{(E I)_{\mathrm{cal}}}$

If a failure criteria for combined tension and bending stresses in the timber is used, it is necessary to separate the maximum tension stress $\sigma_{\max , t}$ into tension $\sigma_{t}$ and bending $\sigma_{m}$. The tension share $\sigma_{t}$ can be determined by entering the distance $z_{t}$, which is the distance between the neutral axis of the composite beam and that of the timber part, into Eq. 9.

The shear stress in the joint and in the cross-section can be determined with the knowledge of the static moment $S_{i}$ and the shear force $V$. The relationship between shear flow $v_{i}$ (see Eq. 10), shear stress $\tau_{i}$ and the width $b_{i}$ is depicted in Eq. 11 .

$$
\begin{aligned}
S_{i} & =\int_{A} z \cdot \mathrm{d} A \\
\tau_{i} & =\frac{v_{i}}{b_{i}}=\frac{V \cdot S_{i}}{b_{i}} \cdot \frac{E_{i}}{(E I)_{\mathrm{cal}}}
\end{aligned}
$$


Cross section Longitudinal section Bending stress $\left[\mathrm{N} / \mathrm{mm}^{2}\right]$

Shear stress $\left[\mathrm{N} / \mathrm{mm}^{2}\right]$

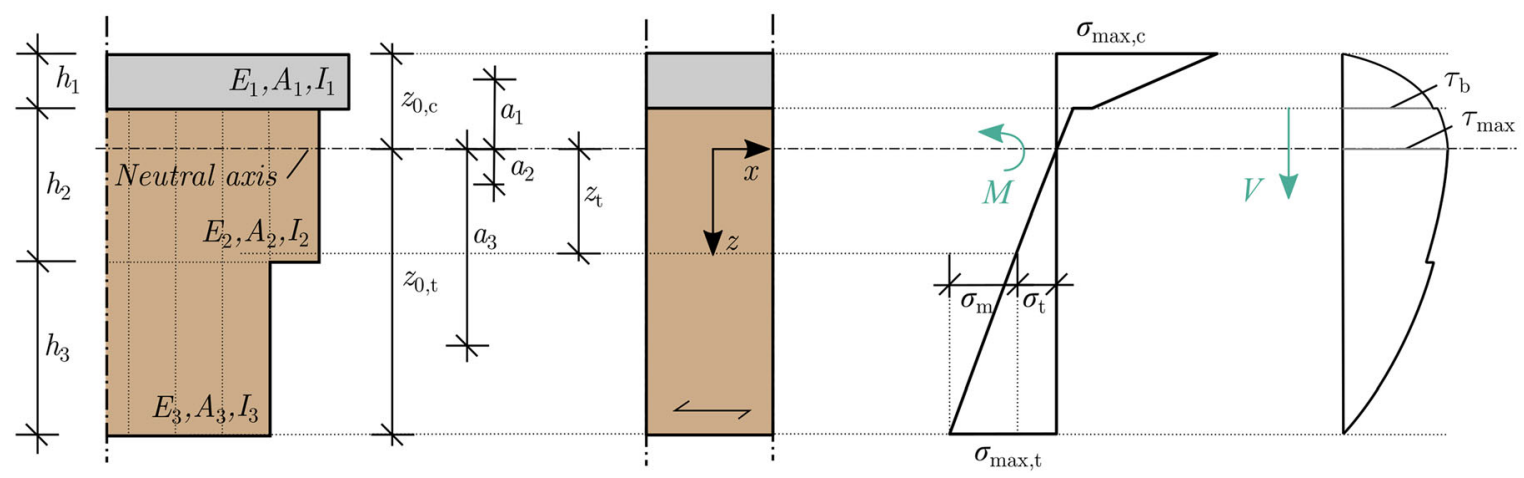

Fig. 10 Composite beam-definition of geometrical dimensions and stress distribution in the cross-section

\subsection{Failure criteria}

Different types of failure can be considered by different failure criteria which take the specific material behavior and material strength into account. Due to the composite action and the static system, which was chosen as a single span girder, the concrete part is strained mainly by compression and the timber part by bending and tension stresses. The stress distributions of the composite beam are depicted in Fig. 10, which is based on linear-elastic stress-strain relationships. Strength values are documented in Sect. 2.2. The relevant failure criteria are:

a. Compression failure of the concrete:

$$
\sigma_{\max , c} / f_{c} \leq 1,0 \text {. }
$$

b. Bond failure of the joint: $\tau_{b} / f_{b} \leq 1,0$.

c. Shear failure of the timber: $\tau_{\max } / f_{v} \leq 1,0$.

d. Tension and bending failure of the timber: $\left(\sigma_{t} / f_{t}\right)+\left(\sigma_{m} / f_{m}\right) \leq 1,0$.

Regarding the failure criteria d, it should be mentioned that the consideration of an interaction of bending and tension strength follows the regulations of Eurocode 5 [12].

\subsection{Prediction of the failure load}

The failure load $F_{u \text {,cal }}$ is calculated in three steps. Firstly, the ultimate section forces $M$ and $V$ are calculated by inserting strength values from Sect. 2.2 into Eqs. 9 and 11. After that, the related loading for the static systems of Fig. 11 can be calculated for every failure criterion separately. The estimated

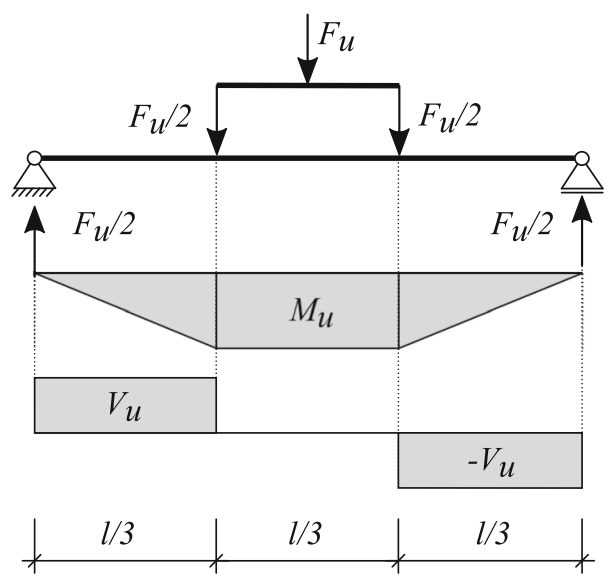

Fig. 11 Static system 4-point-bending test

failure load $F_{u \text {,cal }}$ corresponds with the decisive failure criteria, which gives the smallest value (see Eq. 12). Finally, the contribution of the weight of the specimen $F_{g}$ and of the loading construction $F_{g, l c}$ are subtracted.

$F_{u, \mathrm{cal}}=\min \left\{\begin{array}{c}F_{u, c} \\ F_{u, b} \\ F_{u, v} \\ F_{u, m+t}\end{array}\right\}-F_{g}-F_{g, l c}$

a. Compression failure in the concrete

With Eq. 9, the linear-elastic capacity of the concrete under compression becomes:

$$
F_{u, c}=\frac{6}{l} \cdot \frac{f_{c} \cdot(E I)_{c a l}}{z_{0, c} \cdot E_{1}}
$$


b. Bond failure in the concrete or the timber

With reference to the results of the bond tests presented in Sect. 3.1, it is possible to predict the bond failure of the contact area and the material configuration chosen using Eq. 11 with the parameter of the timbers shear strength $f_{v}$ (see Eq. 14). The parameter $b_{b}$ is defined by the adhesively bonded area. In the case of specimen FB-2EP- $1, b_{b}$ is equal to $b_{2}$, in the case of FB-PM$1, b_{b}$ is equal to the width of the longitudinal strips, which is $55 \mathrm{~cm}$ (see Fig. 5).

$$
F_{u, b}=2 \cdot \frac{f_{v} \cdot b_{b} \cdot(E I)_{c a l}}{b_{1} \cdot h_{1} \cdot a_{1} \cdot E_{1}}
$$

c. Shear failure in the timber

Because the neutral axis is located in the timber part, the maximum shear-stresses appear there as well.

$$
F_{u, v}=2 \cdot \frac{f_{v} \cdot b_{2} \cdot(E I)_{c a l}}{\left.\left(b_{2} \cdot \frac{\left(z_{0, t}-h_{3}\right)^{2}}{2}+b_{3} \cdot h_{3} \cdot a_{3}\right)\right) \cdot E_{2}}
$$

d. Tension failure of the timber-tension and bending strength

If the cross-section is strained by tension and bending stresses, Eurocode 5 recommends considering a combined failure criteria where both tension and bending strength are included. The COST-Technical Specification [4] follows that recommendation for TCC beams because the timber part is also strained by both tension and bending stresses due to the composite action.

$$
F_{u, m+t}=\frac{6}{l} \cdot \frac{(E I)_{\mathrm{cal}}}{\left(\frac{z_{t}}{f_{t}}+\frac{z_{0, t}-z_{t}}{f_{m}}\right) \cdot E_{2}}
$$

In order to predict the failure load $F_{u \text {,cal }}$ of the composite beam, it is necessary to insert the values of the bending stiffness $(E I)_{\mathrm{cal}}=580,704,500 \mathrm{kNcm}^{2}$ of Eq. 9 and the material strength values of Sect. 2.2 on the Eqs. 13 to 16. Accordingly, Eq. 17 can be derived and the minimum decisive failure load can be calculated. Furthermore, the loads $F_{g}=18.5 \mathrm{kN}$ and $F_{g, l c}=5.5 \mathrm{kN}$ are subtracted.

$$
\begin{gathered}
F_{u, \mathrm{cal}}=\min \left\{\begin{array}{c}
F_{u, c}=518 \mathrm{kN} \\
F_{u, b}=984 \mathrm{kN} \\
F_{u, v}=1668 \mathrm{kN} \\
F_{u, m+t}=494 \mathrm{kN}
\end{array}\right\} \\
-F_{g}-F_{g, l c}=470 \mathrm{kN}
\end{gathered}
$$

It becomes clear that the failure is expected to take place as a tension failure in the timber part.

The midspan deflection $w$ of the ATCC beams can be calculated according to Eq. 18 with knowledge of the bending stiffness $(E I)_{\text {cal }}$ from Eq. 8 .

$$
w=\frac{23 \cdot \frac{F}{2} \cdot l^{3}}{648 \cdot(E I)_{\mathrm{cal}}}
$$

\subsection{FE model}

An alternative approach for the calculation of the deformations and stresses of the ATCC beams can be an FE model. In this case, a 2D FE model with shell elements was generated with the Dlubal software package RFEM 5 [27] in order to calculate the maximum bending stresses and deflections. The concrete was modeled linear-elastically whereas orthotropic behavior was taken into account for the timber parts. The material values were implemented as presented in Tables 1 and 2, whereby the suggestions of fib Model Code [24] were followed for $E_{c}$ and $G_{c}$ for the concrete. A minimum number of eight finite elements over the height of the beam were chosen for the FE mesh (see Fig. 12). The adhesive bond has been implemented as a rigid connection since no considerable relative displacement between timber and concrete were observed in the tests.

Figure 12 shows the deflection of the ATCC beam and the maximum shear and bending stress distributions at $l=1 / 6$ and $l=1 / 2$ respectively for a load of $100 \mathrm{kN}$. With the knowledge of the deflection $w_{1}$ and $w_{2}$ in the range of $\Delta F=100 \mathrm{kN}$, the deformation parameter $\Delta w_{1 / 2, \text { cal }}$ can be calculated similarly to Eq. 7 to $1.69 \mathrm{~mm}$. Moreover, the bending stresses $\sigma_{m, u}$ for the experimentally determined failure load can be calculated by loading the beam with $F_{u \text {,exp,mean }}=446$ $\mathrm{kN}$, the weight of the specimen $F_{g}=18.5 \mathrm{kN}$ and the loading construction $F_{g, l c}=5.5 \mathrm{kN}$ as well as the failure load $F_{u \text {,cal }}=475 \mathrm{kN}$ according to failure criteria $\mathrm{d}$ (combined tension and bending failure, see 


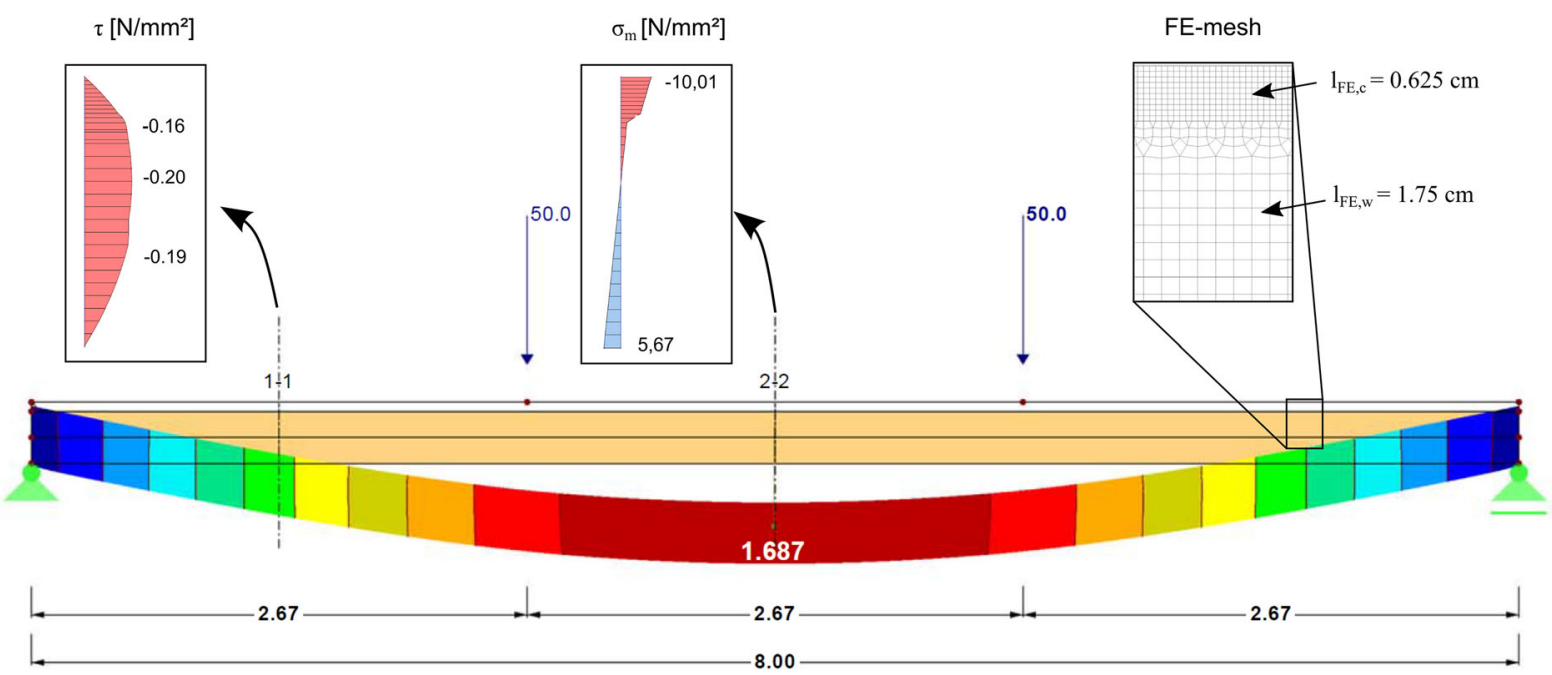

Fig. 12 FE model: details, mesh size, deflection and stress distribution for $F=100 \mathrm{kN}$

Sect. 4.3). All values are summarized in Table 6 and discussed in the model validation Sect. 5 .

\section{Model validation}

A possibility to validate the models which were presented in Sect. 4 is to compare them to the experimental results. The parameters which are included for comparison are the deformation parameter $\Delta w_{1 / 2}$ and the load bearing capacity of the ATCC composite beams $F_{u}$.

\subsection{Deformation behaviour}

The deformation behaviour or rather the stiffness of the ATCC beams can be displayed in the form of loaddisplacement curves (see Fig. 13a). The data line of a situation where only the timber beam was tested is also included for comparison. It can be seen that the loaddisplacement curve of the timber beam is linearelastic, and if Eq. 18 is applied to determine the Young's Modulus, $E_{t, \text { exp }}$ becomes 12,220 N/mm², which stands in good accordance with the expected value of $E_{t, \text { mean }}=12,100 \mathrm{~N} / \mathrm{mm}^{2}$ provided by $\mathrm{EN}$ 14080 [26].

The load-displacement curves of the ATCC composite beams are also almost linear. The determination of the deformation characteristic $\Delta w_{1 / 2, \exp }$ in the range of 10 and $40 \%$ of the ultimate failure load is also graphically displayed in Fig. 13b.

It is necessary to calculate the stiffness parameter $\Delta w_{1 / 2, \text { cal }}$ to compare the deformation behaviour of the analytical model and the FE-model with the test results. The values are summarized in Table 6 .

It can be seen that a difference of about $12 \%$ remains comparing the analytical model with the experimental value, whereby the accordance is better for the FE model with a discrepancy of only $3 \%$.

A possibility to improve the accordance between the analytical model and experimental results could be to consider shear deformations as well. Consequently, an accordance of 1.06 can be achieved, which indicates that it could be useful to consider both bending and shear deformations in the analytical calculation particularly because the stiffness of fullscale beams is one of the most important design parameters. Details of the calculation of the shear deformation are outlined in the appendix.

However, taking into account that the comparison is based on only five full-scale specimens, every accordance in the range of 1.03 to 1.12 can be evaluated as satisfying.

\subsection{Load-bearing capacity and failure mode}

A comparison between the ultimate failure loads which were obtained from the bending tests $F_{u, \exp }$ has been compared to the failure loads calculated $F_{u, c a l}$ to 


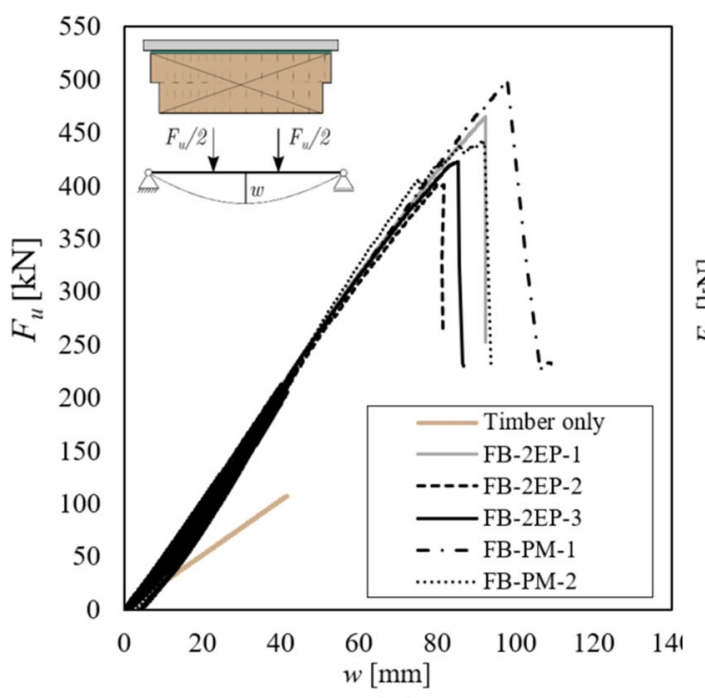

(a)

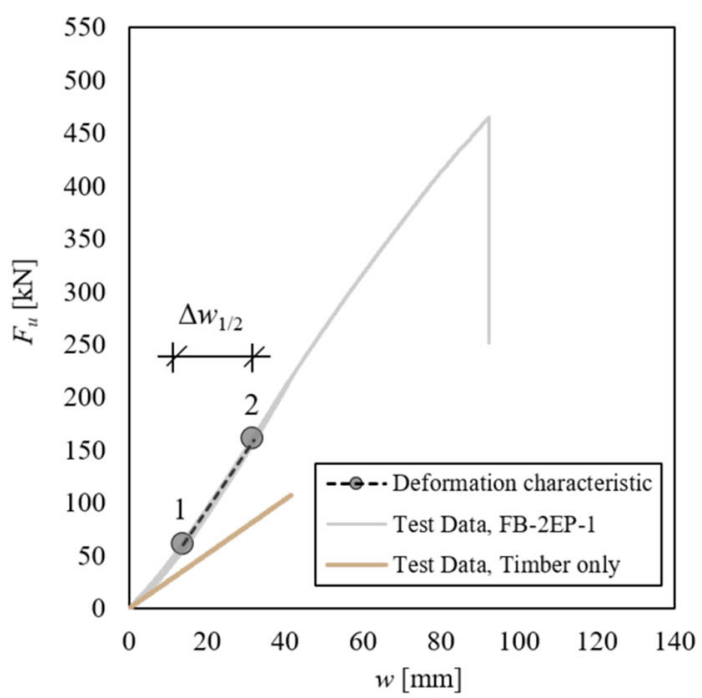

(b)

Fig. 13 Load-displacement diagram: a Test results for full-scale beams b Deformation parameter $\Delta w_{1 / 2}$-comparison of test results and analytical model

validate the model by means of their load bearing capacity. The failure criteria $\mathrm{d}$ from Sect. 4.3 is applied for the calculation of $F_{u, c a l}$.

A good accordance of 0.95 can be detected when comparing $F_{u, c a l}$ from the analytical model with $F_{u, \text { exp,mean }}($ see Table 6). Unlike the comparison of the deformation, it is not possible to achieve a better accordance by applying the FE model. Here, the accordance is in the same range of 0.94. The explanation can be found in the maximum bending stresses for the failure load $\sigma_{m, u}$, which are almost the same. It can be seen that, although the deformation parameter $\Delta w_{1 / 2}$ of both models differs, the prediction of the failure load is most probably the same.

It becomes clear that both models stand in good accordance to the test results and can be recommended for further use.

Taking a closer look at the cyclic loading, it is remarkable that the experimental failure load $F_{u, \text { exp,mean }}$ of all tests is about $10 \%$ smaller than the failure load of the two specimens which were loaded with 2,500 cycles before being tested until failure. The failure under cyclic loading in both specimens was initiated by irregularities in either the timber (knots) or the concrete (anchoring sleeves). Therefore, it cannot be denied that the cyclic loading reduced the loadbearing capacity. The question is whether this reduction can be interpreted as a pure testing phenomena or not, because these kind of anchoring points for example, would not be present in a real beam. In addition, an open question is whether it is possible to consider the decreased failure load due to cyclic loading with the calculation approaches available or if additional testing is necessary. At this point, it should be mentioned, however, that the adhesive bond did not seem to be affected by the cyclic loading. Additional research would help to clarify the question about degradation due to cyclic loading.

Comparing the failure modes as calculated to experimental results, a difference can be seen. While the calculation predicts that the failure takes place in the timber, three beams showed a failure in the concrete at the anchoring sleeves because of structural irregularities. If these tests were excluded from the analysis, the accordance between test and model (see Table 6) would be improved and the accordance between $F_{u, e x p}$ and $F_{u, c a l}$ would become larger than 1.0 .

At this point, it should be noted that although a satisfying correlation between test and model can be seen both in deformation behavior and in load-bearing capacity, the validation of the model is affected by certain parameters. These are in particular:

- geometrical irregularities,

- the consideration of shear deformations, 
Table 6 Comparison between test and calculation

\begin{tabular}{llllll}
\hline & $\Delta w_{1 / 2}(\mathrm{~cm})^{\mathrm{a}}$ & $\begin{array}{l}\Delta w_{1 / 2, \exp } / \\
\Delta w_{1 / 2, \text { cal }}[-]\end{array}$ & $\begin{array}{l}\sigma_{m, u} \\
{\left[\mathrm{~N} / \mathrm{mm}^{2}\right]^{\mathrm{b}}}\end{array}$ & $\begin{array}{l}F_{u} \\
{[\mathrm{kN}]}\end{array}$ & $\begin{array}{l}F_{u, \text { exp }} / \\
F_{u, \text { cal }}[-]\end{array}$ \\
\hline Analytical model $\left(w_{m}\right)$ & 1.56 & 1.12 & 26.7 & 470 & 0.95 \\
Analytical model $\left(w_{m}+w_{v}\right)$ & 1.65 & 1.06 & - & - & - \\
FE-model & 1.69 & 1.03 & 26.6 & 475 & 0.94 \\
Experimental & 1.74 & - & - & 446 & - \\
\hline
\end{tabular}

- material parameters $E_{\text {mean }}$ and $G_{\text {mean }}$, and the

- material strength parameters $f_{t, \text { mean }}, f_{m \text {,mean }}$ and $f_{c, \text { mean }}$.

In this study, these parameters were either experimentally determined or estimated based on literature studies, codes and guidelines. As a result, it should be outlined that the comparatively simple analytical model leads to remarkably accurate results when the mean material parameters are estimated in conformity with literature studies, codes and guidelines.

\section{Summary and outlook}

To conclude, one might say that it was possible to test full-scale specimens successfully using two different types of adhesives and different geometries of the bonding area. Furthermore, a first step validation of the analytical model for load-bearing capacity and deformation characteristics was conducted successfully. With reference to the objectives as defined in Sect. 1.3, the following points can be summarized:

Manufacturing method: The manufacturing process is characterized by the demand to couple timber and concrete prefab continuously by use of an adhesive. To do so, the adhesive has to, firstly, offer sufficient bridging between the uneven surfaces of the two composite materials and, secondly ensure a strong adhesion bond so that failure occurs either in the timber or the concrete rather than at the adhesion surface. Both could be achieved with the methods presented and unevenness in the concrete surface of about $\pm 3 \mathrm{~mm}$, measured via laser scanning technology, could be bridged.

New materials: The application and bonding behavior of two adhesives (2EP and PM) were investigated in small-scale bond samples and fullscale composite beams. Both adhesives proved to be successful on the small- and on the full-scale. A continuous contact between the timber and concrete could always be achieved. Nevertheless, the PM, which is a comparatively new material for bonding timber and concrete, showed strong advantages in terms of the applicability and bridging of gaps and exhibited an excellence performance.

Bonding larger surfaces (instead of beams): Regarding the geometry of the adhesive joint and its correlation with the failure load and mode, it could be seen that it is possible to reduce the amount of PM adhesive by using lateral or longitudinal strips instead of gluing the whole area and achieve a full bond anyway.

Full-scale testing: The performance of ATCC beams was investigated in full-scale bending tests with a span of $8.0 \mathrm{~m}$. The failure took place as either a bending and tension failure of the timber or a compression failure of the concrete. In some cases, local irregularities favored the collapse. Full bonding always remained until the ultimate failure and no delamination could be detected. This clearly underlines the suitability of the gluing technology for the use and fabrication of timber-concrete composite beams.

Modelling: Two models were chosen to analyze the test results: a comparatively simple analytical calculation model based on linear-elastic beam theory and a 2D FE model. The relevant parameters influencing the analysis were discussed. As a result, the decisive failure criteria could be identified as a tension and bending failure in the timber. Validating the mechanical model, it could be seen that there is a sufficient correlation between the results from testing and from calculation for the failure load as well as for the deformation. Furthermore, it could be proved that a more sophisticated FE model does not necessarily provide a deeper insight into the prediction of the deformation and failure modes. The mechanical model, as presented in Sect. 4, is a robust and reliable 
method for the calculation of ATCC beams to provide the basic performance parameters, which are loadbearing capacity and deformation behavior. For the calculation of $(E I)_{\text {cal }}$, however, a consideration of the shear deformations might be beneficial for achieving an even better accordance between the analytically calculated deformation and the deformation of the ATCC beams in the test.

Future research will be carried out regarding an optimization of the adhesives in terms of temperaturecontrolled curing and their rheological behavior (see Mérono et al. [28]). The latter could be improved by using low-viscous 2EP adhesives with inorganic and chemically inert fillers (e.g. silica sand or aerosil). The adhesive develops a better geometrical stability and the gaps between timber and concrete can be filled completely by adding fillers. Furthermore, other materials will be investigated, for example, beech laminated veneer lumber and concrete prefabs with smooth surfaces (see Frohnmüller et al. [29]). Moreover, the durability of the adhesive bond between timber and concrete will be studied more systematically in the future. This includes investigations into variable climates regarding temperature and moisture content.

Comprehensive testing under cyclic loading is necessary to qualify the use of ATCC for bridge structures and provide a basis for design against fatigue failure. This includes medium-scale bond specimens and full-scale composite beams.

Acknowledgements The experimental campaigns were part of the ZIM-research project "Development of adhesively bonded timber-concrete composite bridges for heavy-loading and up to $16 \mathrm{~m}$ - span" between the University of Kassel and Schaffitzel Holzindustrie GmbH + Co. KG, Germany. The project is supported by the German Federal Ministry of Economics and Technology under the reference code KF2512006KI4. The authors would like to thank the research associations which funded and supervised the project. Moreover, thanks goes to the association Lübbert Warenhandel $\mathrm{GmbH}$ und Co. KG for the provision of adhesives.

Funding Open Access funding enabled and organized by Projekt DEAL.

\section{Declarations}

Conflict of interest The authors declare that they have no conflicts of interest.
Open Access This article is licensed under a Creative Commons Attribution 4.0 International License, which permits use, sharing, adaptation, distribution and reproduction in any medium or format, as long as you give appropriate credit to the original author(s) and the source, provide a link to the Creative Commons licence, and indicate if changes were made. The images or other third party material in this article are included in the article's Creative Commons licence, unless indicated otherwise in a credit line to the material. If material is not included in the article's Creative Commons licence and your intended use is not permitted by statutory regulation or exceeds the permitted use, you will need to obtain permission directly from the copyright holder. To view a copy of this licence, visit http://creativecommons.org/licenses/by/4.0/.

\section{Appendix: Considerations on the shear deformation}

In order to elaborate how shear deformations could affect the deformation behavior of the ATCC beams, the shear stiffness of the composite beam $(G A)_{\text {comp }}$ will be calculated in this section. A possible approach to determine $(G A)_{\text {comp }}$ is considering the shear modulus $G_{i}$ and the area $A_{i}$ of the sections weighted by a factor $\delta_{i}$, see Eq. 19 .

$$
(G A)_{\text {comp }}=\sum G_{i} \cdot A_{i} \cdot \delta_{i}
$$

The factor $\delta_{i}$ stands for the part of the cross-section which is strained by the mean value of the shear stress $\overline{\tau_{i}}$ related to the sum of the shear stress of the whole composite beam. The mean shear stress $\overline{\tau_{i}}$ can thereby be calculated from shear stress values at the upper $\left(\tau_{i, u}\right)$ and the lower $\left(\tau_{i, l}\right)$ edge of the section.

$$
\delta_{i}=\frac{\overline{\tau_{i}}}{\sum \overline{\tau_{i}}}=\frac{\frac{\tau_{i, u}+\tau_{i, l}}{2}}{\sum \overline{\tau_{i}}}
$$

The shear stress $\tau_{i}$ can then be calculated with Eq. 11 from Sect. 4.1 for every point of the cross-section. In this case, this is done for the characteristic points of the cross-section, which are the points where the material and the cross-sectional width $b$ change and in the neutral axis where the maximum shear stress occurs (see Fig. 14).

The shear stiffness of the composite beam $(G A)_{\text {comp }}$ can then be calculated step by step. By restructuring Eq. 19 separately for concrete and timber as depicted in Eq. 21, it can be seen that the share of the concrete part on $(G A)_{\text {comp }}$ is $13.2 \%$ and the share of the timber 


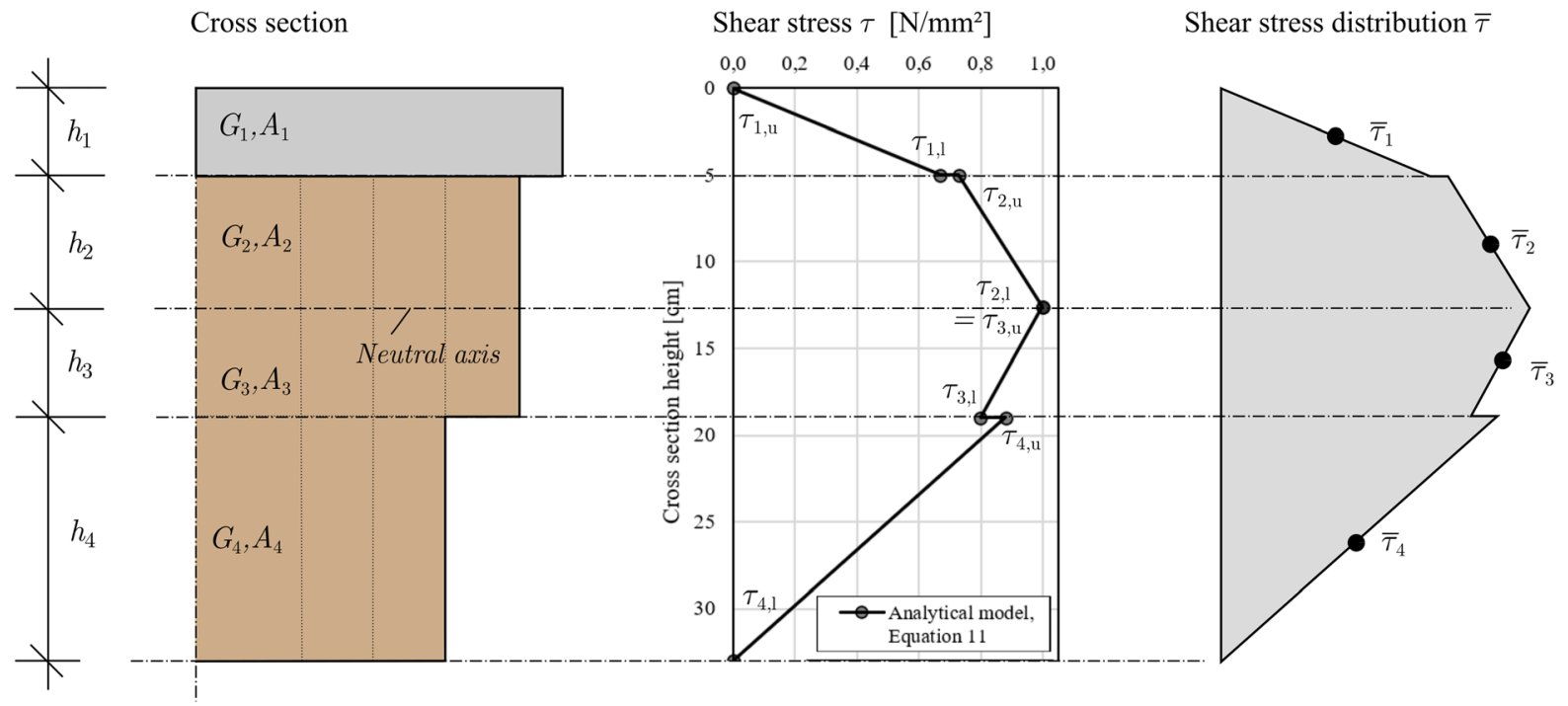

Fig. 14 Shear distribution over the cross section

part is dominant with $86.8 \%$. All in all, the shear stiffness $(G A)_{\text {comp }}$ is $287,420 \mathrm{kNcm}^{2} / \mathrm{cm}^{2}$ in this case.

$$
\begin{aligned}
& (G A)_{\text {comp }}=G_{1} \cdot A_{1} \cdot \delta_{1}+\sum_{i=2}^{i=4} G_{i} \cdot A_{i} \cdot \delta_{i} \\
& =1438 \frac{\mathrm{kN}}{\mathrm{cm}^{2}} \cdot 600 \mathrm{~cm}^{2} \cdot 0.132 \\
& \quad+68 \frac{\mathrm{kN}}{\mathrm{cm}^{2}} \cdot 2940 \mathrm{~cm}^{2} \cdot 0.868 \\
& =287,420 \mathrm{kNcm}^{2} / \mathrm{cm}^{2}
\end{aligned}
$$

With the knowledge of $(G A)_{\text {comp }}$, the shear deformation $w_{V}$ can be determined in the next step by means of the principle of virtual displacements:

$$
\begin{aligned}
& W_{a}=W_{i} \\
& 2 \cdot \frac{F}{2} \cdot \frac{l}{3}=2 \cdot \frac{1}{2} \cdot(G A)_{c o m p} \cdot w_{v} \\
& w_{V}=\frac{F \cdot l}{3 \cdot(G A)_{c o m p}}
\end{aligned}
$$

For a load of $100 \mathrm{kN}$, the shear deformation $w_{v}$ is 0.09 $\mathrm{cm}$. Comparing $w_{v}=0.09 \mathrm{~cm}$ to $w_{m}=1.56 \mathrm{~cm}$ from Eq. 18, it becomes clear that the shear deformation's share in the overall stiffness of the ATCC beam is about $6 \%$. Correspondingly, the accordance between experiment and calculation is 1.06. The values are summarized in Table 6.

\section{References}

1. Green M, Taggart J (2020) Tall wood buildings: design, construction and performance - LCT One - Dornbirn, Birkhäuser, pp 166-175

2. Renaudin F, Jandin P (2017) Design of wood-concrete composite beams under deck bridge, Theoretical developments and construction examples. ICTB 2017, Skelleftea, Sweden

3. Miebach F, Niewerth D (2015) Neue Holz-Beton-Verbundbrücke in Lohmar, Stuttgart, Germany, 3. Stuttgarter Holzbau-Symposium (In German)

4. Dias A, Schänzlin J, Dietsch P (2018) Design of timberconcrete composite structures. COST Action FP1402/WG 4, A state-of-the-art report

5. Tannert T, Gerber A, Vallee T (2020) Hybrid adhesively bonded timber-concrete-composite floors. Int $\mathrm{J}$ Adhes Adhes 97:102490

6. Brunner M, Romer M, Schnüriger M (2007) Timber-concrete-composite with an adhesive connector (wet on wet process). Mater Struct 40:119-126

7. Eisenhut L, Seim W, Kühlborn S (2016) Adhesive-bonded timber-concrete composites - Experimental and numerical investigation of hygro-thermal effects. Eng Struct 125:167-178

8. Pincus G (1978) Epoxy bonded wood-concrete and corrugated steel-concrete composite. International Conference on Materials and Constructions for Developing Countries, Bangkok, Thailand 
9. Schäfers M, Seim W (2011) Investigation on bonding between timber and ultra-high performance concrete (UHPC). Constr Build Mater 25(7):3078-3088

10. Ben Mekki O, Toutlemonde F (2011) Experimental validation of a 10-m-span composite UHPFRC-carbon fiberstimber bridge concept. J Bridge Eng 16(1):148-157

11. Negrão JH, Oliveira FM, Oliveira CA, Cachim BA (2010) Glued composite timber-concrete beams II: analysis and tests of beam specimens. J Struct Eng 136(10):1246-1454

12. EN 1995-1-1: Eurocode 5 (2010) Design of timber structures - Part 1-1: General - Common rules and rules for buildings. EN 1995-1-1:2004+AC:2006+A1:2008

13. Kästner M, Rautenstrauch K (2016) Efficient shear transfer in timber concrete-composite bridges by means of grouting with polymer mortar. WCTE 2016, Vienna, Austria

14. Kästner M (2019) Zum Tragverhalten von PolymermörtelKlebeverbindungen für die Anwendung bei Straßenbrücken in Holz-Beton-Verbundbauweise. Dissertation, BauhausUniversität Weimar (In German)

15. Sika AG (2015) Sikadur 330, Product Data Sheet

16. RAMPF Machine Systems GmbH \& Co. KG (2015) EPUMENT 130/3, Technical data sheet

17. Kühlborn S, Seim W (2016) Geklebter Holz-Beton-Verbund, Projektstudie und grundlegende Untersuchungen. 4. Internationale Holzbrückentage IHB 2016, Biel (In German)

18. Johann Heinrich von Thünen-Institut (2012) Dritte Bundeswaldinventur. https://bwi.info/

19. EN 408:2012-10, (2012) Timber structures - Structural timber and glued laminated timber - Determination of some physical and mechanical properties. EN 408:2010+A1:2012

20. EN 14358 (2016) Timber structures - Calculation and verification of characteristic values. EN 14358:2016
21. JCSS P.M.C (2006) Probabilistic Model Code, Part 3: Resistance Models, Properties of Timber

22. Rehm G, Franke L (1982) Kleben im Konstruktiven Betonbau. Ernst \& Sohn Verlag, Berlin (In German)

23. EN 1992-1-1: Eurocode 2 (2011) Design of concrete structures - Part 1-1: General rules and rules for buildings. EN 1992-1-1:2004 + AC:2010

24. Model Code for Concrete Structures 2010 (2013) Fédération internationale du Béton: fib. Ernst \& Sohn

25. Braun M (2021) Optimierung der Fugengeometrie von geklebten Holz-Beton-Verbundbauteilen mit Verbund durch Fugenverguss, Masterthesis. Universität Kassel, Kassel (In German)

26. EN 14080 (2013) Timber structures - Glued laminated timber and glued solid timber - Requirements. EN 14080:2013

27. RFEM: FEM structural analysis software for structural engineers. Dlubal Software GmbH. 5.25 (Windows 10). 2021

28. Mérono M, Link C, Wisner G, Stammen E, Dilger K, Frohnmüller J, Seim W (2019) Innovative Heißverklebung von tragenden Holz-Beton-Verbundelementen. Adheas Kleb Dict 12:32-37 (In German)

29. Frohnmüller J, Seim W, Mérono M, Wisner G, Stammen E, (2021) Adhesively bonded timber-concrete composites with smooth concrete surfaces. World Conference on Timber Engineering (WCTE), Santiago, Chile

Publisher's Note Springer Nature remains neutral with regard to jurisdictional claims in published maps and institutional affiliations. 